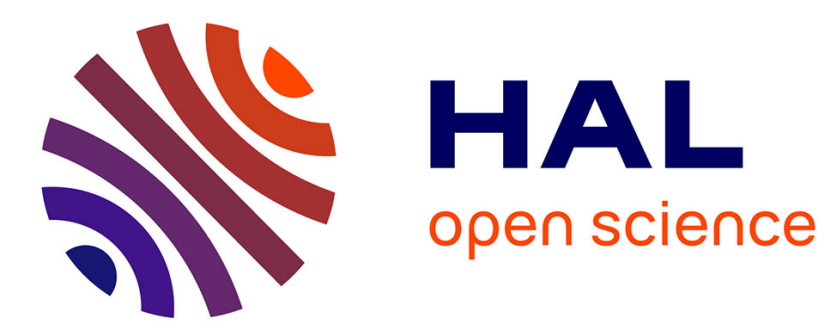

\title{
YBEY is an essential biogenesis factor for mitochondrial ribosomes
}

Sabrina Summer, Anna Smirnova, Alessandro Gabriele, Ursula Toth, Akinyemi Mandela Fasemore, Konrad U Förstner, Lauriane Kuhn, Johana Chicher, Philippe Hammann, Goran Mitulović, et al.

\section{To cite this version:}

Sabrina Summer, Anna Smirnova, Alessandro Gabriele, Ursula Toth, Akinyemi Mandela Fasemore, et al.. YBEY is an essential biogenesis factor for mitochondrial ribosomes. Nucleic Acids Research, 2020, 10.1093/nar/gkaa148. hal-02565858

\section{HAL Id: hal-02565858 https://hal.science/hal-02565858}

Submitted on 6 May 2020

HAL is a multi-disciplinary open access archive for the deposit and dissemination of scientific research documents, whether they are published or not. The documents may come from teaching and research institutions in France or abroad, or from public or private research centers.
L'archive ouverte pluridisciplinaire HAL, est destinée au dépôt et à la diffusion de documents scientifiques de niveau recherche, publiés ou non, émanant des établissements d'enseignement et de recherche français ou étrangers, des laboratoires publics ou privés. 


\title{
YBEY is an essential biogenesis factor for mitochondrial ribosomes
}

\author{
Sabrina Summer ${ }^{1, \dagger}$, Anna Smirnova ${ }^{2, \dagger}$, Alessandro Gabriele ${ }^{2}$, Ursula Toth ${ }^{1}$, \\ Akinyemi Mandela Fasemore ${ }^{\oplus 3}$, Konrad U. Förstner ${ }^{\oplus 3,4,5}$, Lauriane Kuhn ${ }^{6}$, \\ Johana Chicher ${ }^{6}$, Philippe Hammann ${ }^{6}$, Goran Mitulović ${ }^{\circ 7}$, Nina Entelis ${ }^{\oplus 2}$, \\ Ivan Tarassov ${ }^{\circledR 2}$, Walter Rossmanith ${ }^{\oplus 1, *}$ and Alexandre Smirnov ${ }^{\circledR 2,{ }^{*}}$
}

\begin{abstract}
${ }^{1}$ Center for Anatomy \& Cell Biology, Medical University of Vienna, Vienna A-1090, Austria, ${ }^{2}$ UMR7156 - Molecular Genetics, Genomics, Microbiology, University of Strasbourg, CNRS, Strasbourg F-67000, France, ${ }^{3}$ Institute for Molecular Infection Biology, University of Würzburg, Würzburg 97080, Germany, ${ }^{4} \mathrm{TH}$ Köln - University of Applied Sciences, Faculty of Information Science and Communication Studies, Institute of Information Science, Cologne D-50678, Germany, ${ }^{5}$ ZB MED - Information Centre for Life Sciences, Cologne D-50931, Germany, ${ }^{6}$ Proteomics Platform Strasbourg-Esplanade, FRC1589, IBMC, CNRS, Strasbourg F-67000, France and ${ }^{7}$ Proteomics Core Facility, Clinical Department for Laboratory Medicine, Medical University of Vienna, Vienna A-1090, Austria
\end{abstract}

Received December 05, 2019; Revised February 24, 2020; Editorial Decision February 25, 2020; Accepted February 26, 2020

\begin{abstract}
Ribosome biogenesis requires numerous transacting factors, some of which are deeply conserved. In Bacteria, the endoribonuclease $\mathrm{YbeY}$ is believed to be involved in 16S rRNA $3^{\prime}$-end processing and its loss was associated with ribosomal abnormalities. In Eukarya, YBEY appears to generally localize to mitochondria (or chloroplasts). Here we show that the deletion of human YBEY results in a severe respiratory deficiency and morphologically abnormal mitochondria as an apparent consequence of impaired mitochondrial translation. Reduced stability of 12S rRNA and the deficiency of several proteins of the small ribosomal subunit in $Y B E Y$ knockout cells pointed towards a defect in mitochondrial ribosome biogenesis. The specific interaction of mitoribosomal protein uS11m with YBEY suggests that the latter helps to properly incorporate uS11m into the nascent small subunit in its late assembly stage. This scenario shows similarities with final stages of cytosolic ribosome biogenesis, and may represent a late checkpoint before the mitoribosome engages in translation.
\end{abstract}

\section{INTRODUCTION}

Ribosome biogenesis is a highly complex process that starts co-transcriptionally and includes ribosomal RNA process- ing, modification, and binding of ribosomal proteins (1). Each of these steps relies on specific factors, some of which are remarkably conserved. One such factor is the UPF0054 family protein YbeY found in all classified bacteria (2). Based on studies in various bacteria, YbeY has been implicated in ribosome maturation and quality control, with a particularly important role in small subunit (SSU) biogenesis (3-8), and post-transcriptional gene expression regulation (9-14). The deletion of $y b e Y$ is often lethal or associated with severe alterations of cellular metabolism and growth, indicating its indispensability for a wide variety of bacterial-type ribosomes $(4,6,7,13-17)$.

Mechanistically, YbeY has been described as a metaldependent endoribonuclease $(5,12,18)$, and in some bacteria, ybe $Y$ mutants accumulate $16 \mathrm{~S}$ rRNA with an unprocessed $3^{\prime}$ end $(3,5,7,8,18,19)$. Therefore, $Y b e Y$ was proposed to be the 'missing' $3^{\prime}$ ' endoribonuclease required for 16S rRNA maturation to obtain the correct anti-ShineDalgarno sequence, which is needed for translation initiation on most bacterial mRNAs. However, this 16S rRNA $3^{\prime}$-misprocessing phenotype could equally be caused by the loss of a ribosome biogenesis factor that is not per se involved in rRNA cleavage (20), and so the precise role of $\mathrm{YbeY}$ in ribosome biogenesis remains unclear.

By carrying out an in-depth phylogenetic analysis, we found that YBEY is also conserved in many eukaryal lineages, including animals, plants, most stramenopiles and alveolates (Supplementary Figure S1). Indeed, YbeY of Arabidopsis thaliana was reported to be an essential ribosome biogenesis factor in chloroplasts, and its absence was

\footnotetext{
${ }^{*}$ To whom correspondence should be addressed. Tel: +43 140160 37512; Email: walter.rossmanith@meduniwien.ac.at

Correspondence may also be addressed to Alexandre Smirnov. Tel: +33368 85 14 81; Email: alexandresmirnov@unistra.fr

${ }^{\dagger}$ The authors wish it to be known that, in their opinion, the first two authors should be regarded as Joint First Authors.

(C) The Author(s) 2020. Published by Oxford University Press on behalf of Nucleic Acids Research.

This is an Open Access article distributed under the terms of the Creative Commons Attribution License (http://creativecommons.org/licenses/by/4.0/), which permits unrestricted reuse, distribution, and reproduction in any medium, provided the original work is properly cited.
} 
associated with severe misprocessing of nearly all chloroplast rRNAs, resulting in deficiency of organellar translation, and hence, the absence of photosynthesis (16). Human YBEY, which shares $27 \%$ of identity with YbeY of the $\alpha$-proteobacterium Sinorhizobium meliloti $(15,21)$, has been predicted to localize in mitochondria (22), suggesting a role in human mitochondrial ribosome biogenesis. However, mitochondrial rRNAs are co-transcribed in a polycistronic precursor transcript with flanking tRNAs, and the mitochondrial tRNA processing enzymes RNase $\mathrm{P}$ and RNase $\mathrm{Z}$ are sufficient for their release (23-25). Moreover, mitochondrial mRNAs are leaderless and, therefore, do not rely on Shine-Dalgarno sequences for translation initiation (26). These considerations make an enzyme like YBEY apparently superfluous in the mitochondrial genetic system and raise the questions of why it has been retained in evolution and why, based on results of a recent genome-wide 'death screen', it seems to be required for life (27).

Here, we report a detailed characterization of human YBEY and show that it is, indeed, an essential mitochondrial protein, required for mitochondrial translation and, therefore, cellular respiration. We show that it specifically interacts with the conserved mitochondrial chaperone $\mathrm{p} 32$ and mitoribosomal components and is crucial for the assembly of initiation-competent mitochondrial small subunits, apparently by recruiting the key ribosomal protein $\mathrm{uS} 11 \mathrm{~m}$. This essential pathway, which may be conserved in other bacterial and bacteria-derived (i.e. mitochondria and plastids) genetic systems, shows striking parallels with the final steps of cytosolic small subunit maturation mediated by the adenylate kinase Fap7/hCINAP, suggesting that human cells use conceptually similar mechanisms to complete SSU assembly in the two translationally active compartments.

\section{MATERIALS AND METHODS}

\section{Bacterial strains}

Escherichia coli strains used in this study (Supplementary Table S1) are either BL21 Star (DE3) or Rosetta strains, adapted for recombinant protein production. For regular culturing, bacteria were grown at constant shaking at 200 $\mathrm{rpm}$ at $37^{\circ} \mathrm{C}$ in the standard liquid LB medium in the presence of appropriate antibiotics (in function of the hosted plasmids - see Supplementary Table S1; Rosetta strains were routinely cultured in the presence of $34 \mu \mathrm{g} / \mathrm{ml}$ chloramphenicol; where needed, ampicillin and/or kanamycin were added at 100 and $25 \mu \mathrm{g} / \mathrm{ml}$, respectively).

\section{Human cell lines}

293T-REx (Thermo Fischer Scientific), Flp-In T-REx 293 (Thermo Fischer Scientific), SAL001, HepG2 and HeLa cells (see Supplementary Table S2 for the complete list of used cell lines) were cultured at $37^{\circ} \mathrm{C}, 7 \% \mathrm{CO}_{2}$ in standard Dulbecco's modified Eagle's medium (DMEM) containing $4.5 \mathrm{~g} / 1$ glucose supplemented with $10 \%$ fetal bovine serum. Medium was changed routinely every $48 \mathrm{~h}$. For passaging, cells were washed with $1 \times$ phosphate buffered saline (PBS), resuspended in fresh medium and the required dilution was prepared. $Y B E Y$ knockout cells were maintained in standard medium containing $1 \mathrm{mM}$ pyruvate and $50 \mu \mathrm{g} / \mathrm{ml}$ uridine. Complemented $Y B E Y$ knockout cells were grown in standard DMEM medium supplemented with $5 \mu \mathrm{g} / \mathrm{ml}$ blasticidin and $100 \mu \mathrm{g} / \mathrm{ml}$ zeocin.

For preparation of cell line stocks, confluent cells were harvested at $150 \mathrm{~g}$ for $5 \mathrm{~min}$ and resuspended in freezing medium (DMEM supplemented with 20\% FBS and 10\% dimethyl sulfoxide); $500 \mu$ l aliquots were frozen slowly at $-80^{\circ} \mathrm{C}$ and stored in liquid nitrogen. Each batch of frozen cells was routinely tested for mycoplasma contamination.

All 293T-REx-derived cell lines in this study were authenticated by PCR, Sanger sequencing (for the $Y B E Y$ gene), and western blotting (for the YBEY protein), as described in sections 'CRISPR knockout cell line generation' and 'YBEY knockout complementation'.

SAL001 cells and their corresponding parental control cell line (Flp-In T-REx 293) were induced with 0.1-0.2 $\mathrm{mg} / \mathrm{ml}$ tetracycline to overexpress YBEY-3 $\times$ FLAG $24 \mathrm{~h}$ before the experiment.

\section{CRISPR knockout cell line generation}

The plasmid pX330 (28) was modified to generate pX330g containing a CMV promotor-driven EGFP expression cassette cloned in the NotI/Esp3I sites. pU6-gRNA1 was generated from $\mathrm{pX} 330 \mathrm{~g}$ by cleavage at the XbaI sites and re-ligation to delete the Cas9 expression cassette. For construction of pU6-YBEY-gRNA1 and pU6-YBEY-gRNA2 (from pU6-gRNA1) and pX330g-YBEY-gRNA3 and pX330g-YBEY-gRNA4 (from pX330g), the corresponding vector was digested with BbsI, dephosphorylated and used for ligations as previously described (28). Inserts were prepared by phosphorylation and annealing of the respective oligonucleotide pairs YBEY_gRNA_1f/YBEY_gRNA_1r, YBEY_gRNA_2f/YBEY_gRNA_2r, YBEY_gRNA_3f/Y BEY_gRNA_3r and YBEY_gRNA_4f/YBEY_gRNA_4r (see Supplementary Table S3 for the complete list of oligonucleotides used in this study). pPGK-puro was generated from pX260 (28) by cleavage at the EcoRI and NdeI sites to remove the Cas9 cassette, followed by blunt-ending with Klenow polymerase and re-ligation. All plasmids were verified by Sanger sequencing (primer pX260_1r).

For the generation of $Y B E Y^{+}$and $Y B E Y$ knockout cell lines, subconfluent 293T-REx cells $\left(2 \mathrm{~cm}^{2}\right)$ were transfected with $0.2 \mu \mathrm{g}$ of pU6-YBEY-gRNA1 and 0.4 of $\mu \mathrm{g} \mathrm{pX330g-}$ YBEY-gRNA4 plasmids. To pre-select the successfullytransfected clones, the cells were co-transfected with 0.06 $\mu \mathrm{g}$ of pPGK-puro plasmid. The transfection mix, containing $1.5 \mu \mathrm{l}$ of TurboFect (Thermo Fisher Scientific) and 0.66 $\mu \mathrm{g}$ of DNA in DMEM, was incubated for $15 \mathrm{~min}$ at room temperature and added to the cells. Twenty-four hours after transfection, the cells were transfered for two days in standard medium supplemented with $1 \mu \mathrm{g} / \mathrm{ml}$ puromycin. After pre-selection, the knockout cells were seeded at 1, 2, 4 or 8 cells per well in a 96-well plate in standard medium supplemented with home-made $30 \%$ conditioned medium. Cell clones were isolated and characterized by PCR with YBEY_6f/YBEY_6f primers, yielding a 486 bp product for the WT $Y B E Y$ allele and $201 \mathrm{bp}(\Delta 1), 31 \mathrm{bp}(\Delta 2)$ and 130 bp $(\Delta 3)$ for the disrupted alleles. As in the first round no 
homozygous $Y B E Y$-deletion clones were obtained, three $Y B E Y^{+}$clones were expanded and re-transfected, following the same protocol mentioned above, to generate knockout cells in a second round. $Y B E Y^{+}$clone 1 was transfected with $0.2 \mu \mathrm{g}$ of pU6-YBEY-gRNA2 and $0.4 \mu \mathrm{g}$ of pX330gYBEY-gRNA3; $Y B E Y^{+}$clones 2 and 3 were re-transfected with $0.2 \mu \mathrm{g}$ of pU6-YBEY-gRNA2 and 0.4 of $\mu \mathrm{g}$ pX330gYBEY-gRNA4. Three knockout clones were finally isolated following the same procedure as described above and confirmed by PCR and western blotting.

\section{CRISPR knockout complementation}

To construct the pcDNA4-YBEY plasmid, used for $Y B E Y \mathrm{KO}$ complementation with a WT $Y B E Y$ allele, a PCR product generated with primers YBEY_3f and YBEY_7r, spanning the complete coding sequence of YBEY (167 aa, NM_058181), was inserted into the BamHI and XhoI sites of pcDNA4/TO. Plasmids with mutant $Y B E Y$ alleles (pcDNA4-YBEY-R55A and pcDNA4YBEY-H128A) were generated by QuickChange sitedirected mutagenesis (Agilent) with the following pairs of primers, respectively: YBEY_R55A_1f/YBEY_R55A_1r and SAO00050/SAO0051. All plasmids were verified by Sanger sequencing (primers CMV_for and BGH_rev).

To generate $Y B E Y$ knockout cells stably expressing WT YBEY or the YBEY mutant variants YBEY ${ }^{\mathrm{R} 55 A}$ and YBEY ${ }^{\mathrm{H} 128 \mathrm{~A}}$, subconfluent $Y B E Y$ knockout cells of clones 2 and $3\left(2 \mathrm{~cm}^{2}\right)$ were transfected with ScaI-linearized pcDNA4-YBEY, pcDNA4-YBEY-R55A, or pcDNA4YBEY-H128A, respectively. After $48 \mathrm{~h}$, successfullytransfected cells were selected for 4 weeks using $5 \mu \mathrm{g} / \mathrm{ml}$ blasticidin and $100 \mu \mathrm{g} / \mathrm{ml}$ zeocin. Selected clones were tested for expression of YBEY by western blotting, and the identity of mutations was confirmed by PCR (the insert was amplified with primers CMV-for2 and BGH rev2 and sequenced with YBEY_3f and BGH-rev).

\section{Generation of a stable YBEY-3 x FLAG cell line}

The pSAP0006 plasmid to overexpress YBEY-3 $\times$ FLAG was created by inserting the $Y B E Y$ cDNA (amplified with primers SAO00029/SAO00030) into the ApaI/BspTI sites of pcDNA5 FRT/TO. Flp-In T-REx 293 cells were reversetransfected with a mixture of $0.4 \mu \mathrm{g}$ of pSAP006 and 3.6 $\mu \mathrm{g}$ of pOG44 with $10 \mu \mathrm{l}$ of Lipofectamine 2000 (Thermo Fisher Scientific) in $2 \mathrm{ml}$ of OptiMEM (Gibco) during $6 \mathrm{~h}$. Medium was changed to EMEM, and the cells were left to propagate for $48 \mathrm{~h}$. Then the cells were trypsinized, diluted and reseeded in the presence of $320 \mu \mathrm{g} / \mathrm{ml}$ hygromycin B Gold (InvivoGen). In $48 \mathrm{~h}$, concentration of hygromycin was reduced to $160 \mu \mathrm{g} / \mathrm{ml}$, and 18 days after transfection, individual clones were isolated and propagated in the presence of $160 \mu \mathrm{g} / \mathrm{ml}$ hygromycin. The clone used in this study is referred to as SAL001.

\section{siRNA-mediated gene knockdown}

For $\mathrm{uS} 11 \mathrm{~m}$ silencing, 293T-REx cells were subjected to four sequential reverse transfections with $50 \mathrm{nM}$ siRNA. For this, siRNA was complexed with Lipofectamine
RNAiMAX (Thermo Fisher Scientific) according to the manufacturer's protocol (e.g., for a 24-well plate, $1 \mu 1$ Lipofectamine per $500 \mu$ l of OptiMEM was used) and incubated with cells for $6 \mathrm{~h}$. Between transfections, cells were cultivated in DMEM during 48-72 h. Typically, cells transfected with uS11m-directed siRNAs show fast medium acidification after the fourth transfection, indicating a mitochondrial dysfunction.

\section{Transient complementation of $Y B E Y$ KO}

The pSAP0118 plasmid, representing a pcDNA5 FRT/TO variant with a weakened $(\Delta 5) \mathrm{CMV}$ promoter (29), was generated from pcDNA5 FRT/TO by QuikChange with SAO00217/SAO00218 primers. The same primers were used to derive the pSAP0109 plasmid from pSAP0006, permitting an attenuated YBEY-3 $\times$ FLAG expression upon transfection. To construct an analogous uS11moverexpressing plasmid (pSAP0119), the MRPS11 cDNA was amplified with SAO00210/SAO00211, inserted in the BspTI/ApaI sites of pSAP0118, and the stop-codon was corrected by QuikChange with SAO00219/SAO00220. All plasmids were verified by Sanger sequencing (CMV_for and BGH_rev primers).

For transient transfection, YBEY KO cells (clones 2 and 3) were seeded in a 12-well plate. For complex formation, $1.6 \mu \mathrm{g}$ of plasmid DNA was mixed with $4 \mu \mathrm{l}$ of Lipofectamine 2000 in $1 \mathrm{ml}$ of OptiMEM and added to the cells for $6 \mathrm{~h}$. Then the medium was changed to DMEM. In $48 \mathrm{~h}$, the transfection was repeated, and $72 \mathrm{~h}$ later, the cells were harvested with ice-cold PBS, lysed in $1 \times$ Laemmli buffer and analysed by $12 \%$ SDS-PAGE followed by western blotting.

\section{Western blotting}

Protein samples in Laemmli buffer were resolved by SDSPAGE, the proteins were transferred on an Amersham Protran western blotting nitrocellulose (GE Healthcare) or an Amersham Hybond P PVDF (GE Healthcare) membrane by semi-dry transfer. The membrane was blocked with 1 $\times$ TBS containing $0.1 \%$ Tween-20 and $10 \%$ skimmed milk, and incubated with primary antibodies (see the Supplementary Table S4 for the complete list of antibodies) diluted in $1 \times$ TBS, $0.1 \%$ Tween-20 for $1 \mathrm{~h}$ at room temperature or overnight at $4{ }^{\circ} \mathrm{C}$. The membrane was washed with $1 \times \mathrm{TBS}$, $0.1 \%$ Tween-20 and incubated with a dilution of the corresponding HRP-coupled secondary antibody for $30 \mathrm{~min}$, followed by another round of washing. The chemiluminescent signal was visualized with the SuperSignal West Pico PLUS (Thermo Fisher Scientific), or Westar Sun (Cyanagen), or ECL Select Western blotting (GE Healthcare) chemiluminescent substrate on ChemiDoc Touch (Bio-Rad) or G-Box (Syngene) and analysed with Image Lab (v. 5.2.1).

\section{Northern blotting}

RNA samples mixed 1:1 with the denaturing gel loading buffer $(0.025 \%$ SDS, $18 \mathrm{mM}$ EDTA, 0.025\% bromophenol blue, $0.025 \%$ xylene cyanol in deionized formamide) and boiled for $5 \mathrm{~min}$ at $95^{\circ} \mathrm{C}$ were separated on $6-8 \%$ polyacrylamide $/ 7 \mathrm{M}$ urea denaturing gel in $1 \times \mathrm{TBE}$ and 
transferred onto an Amersham Hybond + membrane (GE Healthcare). RNA was UV-crosslinked to the membrane. Pre-hybridization was performed for $30 \mathrm{~min}$ at $65^{\circ} \mathrm{C}$ in $6 \times$ SSC containing $5 \times$ Denhardt's solution and $0.2 \%$ SDS. The membrane was incubated overnight with a $5^{\prime}-{ }^{32} \mathrm{P}$-labelled probe in $3 \times \mathrm{SSC}, 0.1 \% \mathrm{SDS}, 0.5 \times$ TE, $0.5 \mathrm{M} \mathrm{NaCl}, 5 \times$ Denhardt's solution at $42^{\circ} \mathrm{C}$ with continuous rotation. After hybridization, the membrane was washed with $5 \times \mathrm{SSC}$, $0.1 \%$ SDS, dried and exposed with a Phosphorimager plate. The radioactive signal was visualized on Typhoon Trio (GE Healthcare) and analysed with ImageQuant TL (v. 7.0, GE Healthcare). For re-probing, membranes were stripped in stripping buffer $(1 \%$ SDS, $0.1 \times \mathrm{SSC}, 40 \mathrm{mM}$ Tris- $\mathrm{HCl}, \mathrm{pH}$ 7.6) at $80^{\circ} \mathrm{C}$ three times for 10 minutes and washed once in $2 \times$ SSC.

\section{Subcellular and mitochondrial fractionation}

For subcellular fractionation, confluent 293T-REx cells $\left(25 \mathrm{~cm}^{2}\right)$ were harvested and nuclei were isolated from 5 $\times 10^{6}$ cells with the Qproteome Cell Compartment Kit (QIAGEN), according to the manufacturer's instructions. Lysates were incubated for $30 \mathrm{~min}$ on an end-over shaker at $4^{\circ} \mathrm{C}$ and centrifuged at $6000 \mathrm{~g}$ at $4^{\circ} \mathrm{C}$.

Mitochondria were prepared from $1 \times 10^{7}$ 293T-REx cells. Cells were washed twice with $1 \times$ PBS and resuspended in $400 \mu \mathrm{l}$ of chilled RSB buffer $(10 \mathrm{mM}$ Tris- $\mathrm{HCl}, \mathrm{pH} 7.6$, $10 \mathrm{mM} \mathrm{NaCl}, 1.5 \mathrm{mM} \mathrm{CaCl}_{2}$ ). Cells were incubated for 15 min on ice, homogenized with a $27 \mathrm{G}$ needle on a $1 \mathrm{ml}$ syringe, and 1 volume of chilled MS buffer ( $420 \mathrm{mM}$ mannitol, $140 \mathrm{mM}$ sucrose, $10 \mathrm{mM}$ Tris-HCl, $\mathrm{pH}$ 7.6, $5 \mathrm{mM}$ EDTA) was added. Cell debris was pelleted by centrifugation at $4{ }^{\circ} \mathrm{C}$ as follows: $2 \mathrm{~min}$ at $500 \mathrm{~g}$, twice $2 \mathrm{~min}$ at $1000 \mathrm{~g}$, with transferring the supernatants to fresh tubes after each centrifugation. Mitochondria were pelleted at $10000 \mathrm{~g}$ at $4{ }^{\circ} \mathrm{C}$ for $8 \mathrm{~min}$, washed once with chilled M3 buffer (210 mM mannitol, $70 \mathrm{mM}$ sucrose, $20 \mathrm{mM}$ Tris- $\mathrm{HCl}, \mathrm{pH} 7.6,10 \mathrm{mM}$ $\mathrm{KCl}, 6 \mathrm{mM}$ EDTA) supplemented with $1 \mathrm{mM}$ DTT, 0.1\% proteinase inhibitor cocktail (Roche) and incubated for 10 min on ice in $100 \mu 1$ of chilled M3 buffer supplemented with $1 \mathrm{mM}$ DTT, $0.1 \%$ proteinase inhibitor cocktail and $0.02 \%$ digitonin. Mitochondrial pellets were washed once with chilled M3 buffer supplemented with $1 \mathrm{mM}$ DTT, $0.1 \%$ proteinase inhibitor cocktail. Total cell, mitochondrial and nuclei pellets of 293T-REx cells were resuspended in $1 \times$ PBS and an equivalent of $5 \times 10^{5}$ cells was resolved by $15 \%$ SDS-PAGE. Purity of the fractions and the presence of YBEY in the cellular compartments were analysed by western blotting.

Submitochondrial fractionation was performed as described in (30). Briefly, $225 \mathrm{~cm}^{2}$ of SAL001 cells were grown to $80-90 \%$ confluency and induced with $0.2 \mathrm{mg} / \mathrm{ml}$ tetracycline for $24 \mathrm{~h}$. All subsequent manipulations were carried out at $4{ }^{\circ} \mathrm{C}$. The cells were resuspended in $1.5 \mathrm{ml}$ of Breakage buffer (0.6 M sorbitol, $10 \mathrm{mM}$ HEPES-KOH, $\mathrm{pH} 7.5,1 \mathrm{mM}$ EDTA) and disrupted with a syringe (26G $\times 25 \mathrm{~mm}, 20$ strokes). After two low-speed centrifugations $(600 g$ and $1000 g$ ) for 10 min to remove cell debris and nuclei, the mitochondria-rich fraction was collected by highspeed centrifugation at $14000 \mathrm{~g}$ for $20 \mathrm{~min}$. The pellet was resuspended in $0.5 \mathrm{ml}$ of Breakage buffer, split in three equal aliquots and centrifuged for another $10 \mathrm{~min}$ at $14000 \mathrm{~g}$. The supernatants were discarded. The pellets were resuspended at $0.5 \mathrm{mg} / \mathrm{ml}$ (mitochondrial protein measured by Bradford assay, Roti-Nanoquant, Carl Roth) in one of the following buffers: (i) Breakage buffer; (ii) 'Swelling' buffer (10 mM HEPES-KOH, pH 7.5, 1 mM EDTA); (iii) Lysis buffer (10 mM HEPES-KOH, pH 7.5, 1 mM EDTA, 0.5\% n-dodecyl$\beta$-D-maltoside). The latter sample was additionally lysed with a syringe (10 strokes) to ensure complete membrane solubilization. Each aliquot was then split in two equal portions, one of which was treated with $50 \mu \mathrm{g} / \mathrm{ml}$ proteinase $\mathrm{K}$. The samples were incubated on ice for $20 \mathrm{~min}$, added $1 \mathrm{mM}$ PMSF and 1/4 volume of $100 \%$ trichloroacetic acid (prepared by dissolving $5 \mathrm{~g}$ of TCA in $3.5 \mathrm{ml}$ of water), then incubated on ice for another $10 \mathrm{~min}$. Upon a $10 \mathrm{~min}$ centrifugation at $14000 \mathrm{~g}$, the precipitates were washed twice with ice-cold acetone and dried overnight on bench. They were then resuspended in $100 \mu l$ of $1 \times$ Laemmli buffer, heated for $5 \mathrm{~min}$ at $80^{\circ} \mathrm{C}$ and sonicated. For analysis, $10 \mu \mathrm{l}$ of each sample was resolved by $15 \%$ SDS-PAGE followed by western blotting.

\section{Microscopy and image analysis}

The pSAP0123 plasmid to overexpress YBEY-FLAG was generated from pSAP0006 by QuikChange with primers SAO0225/SAO0226.

For confocal microscopy, cells were seeded on an eightwell Nunc Lab-Tek slides (Thermo Fisher Scientific) 24-48 h prior the experiment. For Flp-In T-REx 293-derived cell lines, the slide was covered with $0.1 \%$ gelatine to improve cell adhesion. For this the slide was incubated with gelatine for $30 \mathrm{~min}$ at $37^{\circ} \mathrm{C}$ at $5 \% \mathrm{CO}_{2}$, then the excess of gelatine was washed out with MilliQ and the slide was dried. For transient transfection of cells with pSAP0123, $150 \mathrm{ng}$ of plasmid DNA was mixed with $0.5 \mu$ l of Lipofectamine 2000 in $300 \mu \mathrm{l}$ of OptiMEM and incubated with adherent cells during 4-6 h. After that, medium was changed to EMEM. In $24 \mathrm{~h}$ post-transfection, cells were fixed by incubation during 12 min at $37^{\circ} \mathrm{C}$ with $3 \%$ formaldehyde solution diluted with the DMEM medium (4\% paraformaldehyde dissolved in PBS by heating at $60^{\circ} \mathrm{C}$ and adjusted to $3 \%$ with DMEM). For immunostaining, the cells were permeabilized with $0.3 \%$ Triton X-100 in $1 \times$ PBS for $10 \mathrm{~min}$ at room temperature. After blocking with 5\% bovine serum albumin (BSA) in $1 \times$ PBS for $30 \mathrm{~min}$ at room temperature, samples were incubated for 1-3 $\mathrm{h}$ with primary antibodies diluted in the blocking buffer, then with secondary antibodies conjugated with respective fluorophores. For nuclear counterstaining, $1 \mu \mathrm{g} / \mathrm{ml}$ DAPI in $1 \times$ PBS was applied for $5 \mathrm{~min}$ at room temperature. Each step alternated with five washes with $1 \times$ PBS. Samples were imaged on LSM700 or LSM780 microscopes (Carl Zeiss) under $63 \times / 1.4$ oil objective in Vectashield (Vector Laboratories) or Prolong Gold (Invitrogen) mounting media. Fluorescence intensity profiles were measured in ImageJ (31). For estimation of the uS11m amount in different cell lines, images were segmented by global $\mathrm{Li}$ thresholding method (32), then mean fluorescence intensity was calculated in ImageJ.

Simultaneous RNA smFISH and protein immunostaining were done according to the manufacturer's protocol 
Nucleic Acids Research, 2020

for the ViewRNA ISH Cell assay kit (Thermo Fisher Scientific). For RNA smFISH, the branched DNA technology was used (33): a gene-specific oligonucleotide target probe set containing $20-40$ probe pairs binds to the target RNA sequence (see the complete list of smFISH probes in Supplementary Table S3), and signal amplification is achieved through a series of sequential hybridization steps with pre-amplifier, amplifier and finally fluorophorelabelled oligonucleotides. For the analysis of RNA abundance in different cell lines, images of the labelled RNA and the mitochondrial reference protein were segmented and subcellular shapes were quantified with the Squassh method (34) in the MosaicSuit in Fiji (35). The obtained mean size of objects representing individual RNAs or groups of RNAs was multiplied by the number of the objects in each frame for estimation of total abundance of RNA. This parameter was then normalized to the total abundance of the mitochondrial reference protein (TOMM20 or mL38) obtained by the same procedure.

For FLIM-FRET analyses, SAL001 cells were immunolabelled, as described above, with primary and secondary antibodies coupled with synthetic fluorophores that form a FRET pair $(36,37)$. The less abundant protein was chosen as fluorescence donor and labelled with Alexa Fluor 488; the more abundant acceptor protein was labelled with Alexa Fluor 555. For testing the YBEY-p32 interaction, YBEY was labelled with YBEY antibodies, in all other cases with FLAG antibodies. Camera-based lifetime detection of donor fluorescence was performed on a widefield microscope FLIM Nikon TE2000 operated in the frequency domain. Before each experiment, the system was calibrated at the pixel level with the reference fluorophore fluorescein with known fluorescence lifetime of $4 \mathrm{~ns}$. The number of analysed frames is shown on Figure 5B.

Transmission electron microscopy was performed at the Plateforme Imagerie In Vitro, CNRS, UPS3156, University of Strasbourg. Briefly, cells were washed with $1 \times$ PBS and fixed with $3 \%$ glutaraldehyde in $0.1 \mathrm{M}$ cacodylate buffer. Then samples were dehydrated in a graded ethanol series, treated with propylene oxide, embedded in araldite resin, cut and mounted on copper grids. Ultrasections were contrasted with uranyl acetate. Specimens were examined with a Hitachi H 7500 microscope equipped with an AMT Hamamatsu digital camera. For quantitative analysis, mitochondria were outlined manually and their area and perimeter determined in ImageJ. The cristae numbers were counted manually and normalized to the mitochondrial area.

\section{MTT cell proliferation assay}

Confluent cells were resuspended and seeded at $1 \times 10^{4}$ cells (for the 2-day time point) and $6 \times 10^{2}$ (for the 6-day time point) per well on a 96-well plate in glucose medium (glucose-free DMEM supplemented with 10\% FBS, $2 \mathrm{mM}$ glutamine and $5 \mathrm{mM}$ glucose) or in galactose medium (glucose-free DMEM supplemented with 10\% FBS, 2 mM glutamine and $5 \mathrm{mM}$ galactose). For each time point and treatment, duplicates were prepared. After 2 and 6 days of growth, respectively, $0.5 \mathrm{mg} / \mathrm{ml}$ thiazolyl blue tetrazolium bromide (MTT) was added to the medium. Cells were incubated for $2 \mathrm{~h}$ and $100 \mu \mathrm{l}$ of isopropanol was added to each well. The absorbance was measured at $570 \mathrm{~nm}$ over $1 \mathrm{~min}$ with the Enspire multimode plate reader (Perkin Elmer). For all values the blank mean was subtracted.

\section{Seahorse respiration phenotype measurements}

Cells were cultivated standardly in the DMEM medium, dissociated with a $0.25 \%$ trypsin-EDTA solution, and their amount was estimated by Sceptor Handled Automated Cell Counter (Millipore). Then the cells were seeded in the DMEM medium on Seahorse XF96 V3 PS cell culture microplates (Seahorse XFe96 FluxPak mini, Agilent) coated with $0.1 \%$ gelatine $24 \mathrm{~h}$ before the experiment. To achieve measurable OCR, 10,000 cells $\left(Y B E Y^{+}\right.$and complemented $Y B E Y \mathrm{KO}$ cell lines) or 30,000 cells (uncomplemented $Y B E Y \mathrm{KO}$ ) per well were seeded. The Seahorse XF Cell Mito Stress test was performed on a Seahorse XFe96 Analyser (Agilent) in the XF Base Medium (Agilent) supplemented with $25 \mathrm{mM}$ glucose, $4 \mathrm{mM}$ glutamine and $1 \mathrm{mM}$ pyruvate $\left(\mathrm{pH} 7.4\right.$ adjusted at $37^{\circ} \mathrm{C}$ with $5 \mathrm{M}$ $\mathrm{NaOH}$ ). Compounds from the Seahorse XF Cell Mito Stress Test Kit (Agilent) were used in the following order and concentrations: $2 \mu \mathrm{M}$ oligomycin, $2 \mu \mathrm{M}$ FCCP, $0.5 \mu \mathrm{M}$ rotenone/antimycin A. Basal respiration was measured as the difference between the OCR before the first injection and the non-mitochondrial respiration rate. ATP production was measured as the difference between the OCR before the oligomycin injection and the minimum OCR after the oligomycin injection. Maximal respiration is the difference between the maximum OCR after the FCCP injection and non-mitochondrial respiration. The latter is defined as the minimum OCR after the rotenone/antimycin A injection. ECAR was measured in the absence of additives. The data were analysed in Wave Desktop and Controller 2.6 (Agilent Technologies).

\section{Respiratory complex activity assays}

Cells $\left(75 \mathrm{~cm}^{2}\right)$ were harvested and washed once with $1 \times$ PBS; $1 \times 10^{7}$ cells were used for mitochondrial preparation by differential centrifugation, as described above. The initial mitochondrial pellets were frozen in liquid nitrogen and stored at $-80^{\circ} \mathrm{C}$ until measurement. Mitochondria from 1 $\times 10^{7}$ cells were resuspended in $100 \mu 1$ of SETH buffer $(250$ mM sucrose, 10 mM Tris- $\mathrm{HCl}, \mathrm{pH}$ 7.4, 2 mM EDTA) and broken by two freeze-thaw cycles of freezing in liquid nitrogen and thawing on ice. Mitochondrial lysates were gently resuspended before the use in activity measurements.

For spectrophotometric measurements a UV-Vis spectrophotometer (Shimadzu UV-1800) was used. Complex I activity was determined by measuring the rotenonesensitive NADH oxidation at $334 \mathrm{~nm}$ at $30^{\circ} \mathrm{C}$ with the use of decylubiquinone as electron acceptor. For this, $30 \mu \mathrm{l}$ of mitochondrial lysate was used in a total reaction volume of $750 \mu \mathrm{l}$. The reaction was performed in $25 \mathrm{mM}$ potassium phosphate buffer, $\mathrm{pH} 7.4$, containing $2.8 \mathrm{mg} / \mathrm{ml} \mathrm{BSA}$, $5 \mathrm{mM} \mathrm{MgCl}_{2}, 0.2 \mathrm{mM} \mathrm{NADH}_{2}, 2 \mathrm{mM} \mathrm{KCN}, 0.1 \mathrm{mM}$ decylubiquinone and $4 \mu \mathrm{M}$ antimycin $\mathrm{A}$. Before adding the sample, the assay buffer was incubated for $5 \mathrm{~min}$ at $30^{\circ} \mathrm{C}$ and background absorbance was followed for $2 \mathrm{~min}$. The sample was added and absorbance measured for $6 \mathrm{~min}$. Rotenone (0.02 $\mathrm{mM})$ was added to inhibit complex I activity, and 
rotenone-insensitive absorbance was measured for $4 \mathrm{~min}$. The complex activity (units/1) was calculated as follows:

$$
\begin{aligned}
\Delta A_{334} / \min = & \Delta A_{334} / \min (\text { sample })-\Delta A_{334} / \min (\text { background }) \\
& -\Delta A_{334} / \min (\text { rotenone })
\end{aligned}
$$

Complex I activity $($ units $/ \mathrm{l})=\frac{\left(\Delta A_{334} / \mathrm{min} \times \text { total assay volume } \times 1000\right)}{(6.18 \times \text { sample volume })}$

Complex IV activity (via oxidation of reduced cytochrome c (II)) was measured at $550 \mathrm{~nm}$ at $30^{\circ} \mathrm{C}$ in the assay buffer containing $85 \mathrm{mM}$ HEPES-NaOH, pH 7.2, and $90 \mu \mathrm{M}$ reduced cytochrome c (II) (Sigma-Aldrich). For reaction, $10 \mu \mathrm{l}$ of mitochondrial lysate were used in a total volume of $750 \mu \mathrm{l}$. After 5 min pre-incubation, the sample was added and absorbance (background sample) at $550 \mathrm{~nm}$ was followed for $8 \mathrm{~min}$ at $30^{\circ} \mathrm{C}$. Potassium hexacyanoferrat (III) was added in a final concentration $64.6 \mu \mathrm{M}$ and the absorbance was followed for another $3 \mathrm{~min}$ at $30^{\circ} \mathrm{C}$. The Complex IV activity (units/1) was calculated as follows:

Complex IV activity $($ units $/ \mathrm{l})=\frac{\left(\Delta A_{550} / \mathrm{min} \times S \times \text { total assay volume } \times 1000\right)}{(\text { used sample volume })}$,

where $S=\left(A_{550}\right.$ (SETH buffer) $-A_{550}$ (background sample))/21.1.

Activity of citrate synthase (CS) was determined by measurement of reduction of acetyl-coenzyme A (Ac-CoA) at $412 \mathrm{~nm}$ at $37^{\circ} \mathrm{C}$. For this, $5 \mu \mathrm{l}$ of mitochondrial lysate was added to $750 \mu \mathrm{l}$ of the reaction buffer containing $0.1 \%$

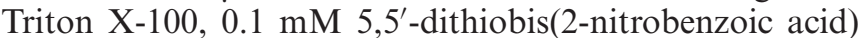
and $0.1235 \mathrm{mM}$ Ac-CoA. The sample was added to the buffer and the background absorbance was measured for 2 min. Then $0.5 \mathrm{mM}$ of freshly prepared oxaloacetic acid was added and the absorbance was measured for another $2 \mathrm{~min}$. Citrate synthase activity (units/l) was calculated as follows:

$$
\Delta A_{412} / \min =\Delta A_{412} / \min (\text { oxaloacetic acid })
$$

$$
-\Delta A_{412} / \min (\text { background sample) }
$$

$\mathrm{CS}$ activity $($ units $/ \mathrm{l})=\frac{\left(\Delta A_{412} / \mathrm{min} \times \text { total assay volume } \times 1000\right)}{(13.6 \times \text { used sample volume })}$

OXPHOS complexes I and IV activities were normalized to CS activity.

\section{Mitochondrial translation assay}

Cells were seeded in the DMEM medium in $10 \mathrm{~cm}^{2}$ sixwell plates pre-treated with $0.1 \%$ gelatine $24 \mathrm{~h}$ before the experiment. The cells were incubated in the RPMI medium without methionine (Gibco) containing $100 \mu \mathrm{g} / \mathrm{ml} \mathrm{eme-}$ tine (Carl Roth) for $10 \mathrm{~min}$ in the cell incubator at $37^{\circ} \mathrm{C}$ and $5 \% \mathrm{CO}_{2}$. Then $140 \mu \mathrm{Ci} / \mathrm{ml}$ EasyTag ${ }^{35} \mathrm{~S}$-L-methionine $(1175 \mathrm{Ci} / \mathrm{mmol}$, Perkin Elmer) was added and cells were incubated for another $30 \mathrm{~min}$. After that $150 \mu \mathrm{g} / \mathrm{ml}$ cold methionine was added for $10 \mathrm{~min}$. Then cells were collected with ice-cold $1 \times$ PBS, pelleted and resuspended in the same buffer. An aliquot was used for protein measurement, the rest was dissolved in Laemmli buffer and sonicated. Samples were heated at $40^{\circ} \mathrm{C}$ for $3 \mathrm{~min}$ and resolved by $12 \%$ SDS-PAGE. Then proteins were transferred onto an Amersham Protran western blotting nitrocellulose membrane (GE Healthcare) by semi-dry transfer. The membrane was dried and the radioactive signal was visualized with
Phosphorimager on Typhoon Trio (GE Healthcare). Images were analysed with ImageQuant TL (v. 7.0, GE Healthcare). After this, western blots were performed as described above.

\section{Mitochondrial DNA copy number measurement}

Cells were seeded on a six-well plate in standard medium, harvested at subconfluency with $1 \times$ PBS and dissolved in PKLB buffer (50 mM Tris- $\mathrm{HCl}, \mathrm{pH} 8,1 \mathrm{mM}$ EDTA, 0.5\% Tween-20) supplemented with $100 \mu \mathrm{g} / \mathrm{ml}$ proteinase $\mathrm{K}$ and $100 \mu \mathrm{g} / \mathrm{ml}$ RNase A. After incubation for $2 \mathrm{~h}$ at $55^{\circ} \mathrm{C}$ with agitating at $1100 \mathrm{rpm}$, the lysate was boiled for $10 \mathrm{~min}$ at $95^{\circ} \mathrm{C}$ and diluted 1:20 in 0.5 $\times$ TE buffer, $\mathrm{pH} 8$, to use directly in a probe-based real-time PCR. TaqMan probes specific for $M T-N D 1$ (mitochondrial DNA-encoded gene) and 18S rRNA (nuclear reference for normalization) were used together with primers 5mtDNA(ND1)1/3mtDNA(ND1)1 (38) and 5_18SrRNA1/ 3_18SrRNA1 (24), respectively.

\section{RT-qPCR}

Cells were harvested and washed with $1 \times$ PBS. Pellets were lysed in RNAzol RT (Molecular Research Center) and total RNA was prepared according to the manufacturer's instructions. For analysis, $250 \mathrm{ng}$ of RNA were treated with DNase I (Thermo Fisher Scientific) and used for cDNA synthesis and RT-PCR, as described in $(24,39)$. RNA levels were determined by real-time qPCR with primers specified in Supplementary Table S3 and normalized to $18 \mathrm{~S}$ rRNA and $U B C$ mRNA levels.

\section{RNA stability measurements}

Cells were seeded at subconfluency in six-well plates, where they were exposed to $250 \mathrm{ng} / \mu$ l ethidium bromide in standard medium to block mitochondrial transcription. For the stability assay, samples from treated cells were taken at 4, 6, 8, 10 and $24 \mathrm{~h}$ and directly lysed in RNAzol for RNA preparation and kept at $-20^{\circ} \mathrm{C}$. RNA was extracted and analysed by RT-qPCR, as described in the corresponding section. RNA levels determined by real-time qPCR were normalized to $18 \mathrm{~S}$ rRNA and $U B C$ mRNA and related to the time point 0 .

\section{Transcriptomic analyses}

Mitochondria of the three $Y B E Y^{+}$and three $Y B E Y$ knockout clones were isolated as described above, dissolved in an equal volume of RiboZol (Amresco), and total RNA was prepared according to the manufacturer's instructions. RNA was dissolved in $0.5 \times$ TE buffer, $\mathrm{pH} 7.5$, and used for cDNA library generation with the NEBNext Ultra kit (New England BioLabs), without enrichment, with short fragmentation, the cutoff size $200-800 \mathrm{bp}$, followed by Illumina HiSeq V4 paired-end sequencing at the VBCF core facility in Vienna. Sequencing read libraries were converted from the BAM format to the FASTQ format with the bamtofastq tool from the BEDTools2 package (v2.26) (40), processed with cutadapt (version 1.15) (41) and then mapped to the Homo sapiens mitochondrial genome (Genbank accession J01415.2) with the use of segemehl (version 0.1.7) 
(42) with -q and -p options for paired reads. The resulting alignment files in the SAM format were converted to BAM files using the Samtools subcommand view (version 1.4) (43) with the flags -bS. Feature quantification was done using featureCounts (version v1.4.6) (44) from the Subread package with the options - T (10) -p -t (exon) -0 -g (gene_id) -s 1 with a manually curated human mitochondrial genome annotation to generate raw read counts. Differential gene expression analysis was performed with the DESeq2 package (version 1.16.1) (45) in R version 3.4.4. RNA-seq tracks were visualized in the Integrated Genome Browser (v. 9.0.2) (46).

\section{cRT-PCR}

Total RNA was isolated from $10 \mathrm{~cm}^{2}$ of cells grown standardly to $80-90 \%$ confluence with TRIzol reagent (Invitrogen), following the manufacturer's protocol. To ensure that all processed transcripts have ligation-competent $5^{\prime}$ phosphate and $3^{\prime}$-hydroxyl termini, $5 \mu \mathrm{g}$ of RNA was treated with $10 \mathrm{U}$ of T4 polynucleotide kinase (Thermo Fisher Scientific) in the presence of $1 \mathrm{mM}$ ATP and $50 \mathrm{U}$ of RNaseOUT (Thermo Fisher Scientific) in $1 \times$ Buffer A (50 mM Tris- $\mathrm{HCl}, \mathrm{pH} 7.5,10 \mathrm{mM} \mathrm{MgCl} 2,5 \mathrm{mM}$ DTT, 0.1 $\mathrm{mM}$ spermidine), according to the manufacturer's protocol, followed by P:C:I extraction.

For circularization, a $20 \mu \mathrm{l}$ reaction, containing 300-1000 ng of RNA, $50 \mathrm{U}$ of RNaseOUT and $10 \mathrm{U}$ of T4 RNA ligase (Thermo Fisher Scientific) in $1 \times$ RNA ligase buffer (50 $\mathrm{mM}$ Tris-HCl, $\mathrm{pH}$ 7.5, $10 \mathrm{mM} \mathrm{MgCl} 2,10 \mathrm{mM}$ DTT, $1 \mathrm{mM}$ ATP), was assembled and incubated overnight at $16-18^{\circ} \mathrm{C}$. In parallel, a control reaction without RNA ligase was performed. Both RNA samples were P:C:I-extracted and 100$400 \mathrm{ng}$ of RNA was used as templates for RT-PCR.

RT-PCRs were performed with the One-step RTPCR kit (QIAGEN) with SAO00187/SAO00188 (for 12S rRNA), SAO00204/SAO00205 (for 16S rRNA), or SAO00191/SAO00192 (for the MT-CO2 mRNA) oligonucleotides as primers with the default manufacturer's protocol. A portion of the RT-PCR samples were visualized by agarose gel electrophoresis followed by ethidium bromide staining to ensure that only circularized RNA gave rise to amplification products. The rest was purified with the GeneJET PCR purification kit (Thermo Fisher Scientific), digested with $\mathrm{XbaI} / \mathrm{KpnI}$ (for $12 \mathrm{~S}$ and $16 \mathrm{~S}$ rRNAs) or PstI/KpnI (for the MT-CO2 mRNA), and P:C:I-extracted.

For cloning, 150-300 ng of the digested RT-PCR product was mixed with 30-50 ng of pUC19, digested with the same restriction endonucleases and dephosphorylated with FastAP (Thermo Fisher Scientific), in the presence of 1 Weiss U of T4 DNA ligase (Thermo Fisher Scientific) in $1 \times$ Ligation buffer $(40 \mathrm{mM}$ Tris- $\mathrm{HCl}, \mathrm{pH} 7.8,10 \mathrm{mM}$ $\mathrm{MgCl}_{2}, 10 \mathrm{mM}$ DTT, $0.5 \mathrm{mM}$ ATP) and incubated on bench overnight. The resulting ligation mixes were used to transform competent XL1 Blue cells. pUC19-containing clones were selected on solid LB medium with $100 \mu \mathrm{g} / \mathrm{ml}$ ampicillin. Typically, $\sim 50$ colonies per plate were screened for the presence of the insert by colony PCR with the M13 reverse and M13 (-21) forward primers. Plasmids from positive clones were sequenced. Sequences were analysed with Chromas (v. 2.6.2) and aligned versus the reference $H$. sapi- ens mitochondrial genome (Genbank accession J01415.2) with BLAST.

\section{Coimmunoprecipitation assay}

For the experiment shown on Figure 5A and Supplementary Table S6, SAL001 cells inducibly overexpressing YBEY-3 $\times$ FLAG were used, while the parental Flp-In TREx 293 cell line served as negative control. In both cases, $900 \mathrm{~cm}^{2}$ of cells were grown and induced, as described in section 'Human cell lines'. Cells were harvested with icecold $1 \times$ PBS, and crude mitochondria were isolated as above and lysed in $0.5 \mathrm{ml}$ of $20 \mathrm{mM}$ Tris- $\mathrm{HCl}, \mathrm{pH} 7.5$, $150 \mathrm{mM} \mathrm{KCl}, 1 \mathrm{mM} \mathrm{MgCl}_{2}, 1 \mathrm{mM} \mathrm{CaCl} 2,1 \mathrm{mM}$ DTT, $0.5 \% \mathrm{n}$-dodecyl- $\beta$-D-maltoside, $1 \mathrm{mM}$ PMSF with the help of a Dounce homogeniser (20 strokes). This and the subsequent manipulations were carried out at $4^{\circ} \mathrm{C}$. The lysate was cleared at $14000 \mathrm{~g}$ for $10 \mathrm{~min}$ and mixed with $50 \mu \mathrm{l}$ of the $\alpha$ FLAG antibody (Sigma-Aldrich, Cat\#F1804), followed by incubation for $30 \mathrm{~min}$ with continuous rocking. Thereafter, the lysate was mixed with $100 \mu 1$ of protein A-sepharose beads (Sigma-Aldrich), pre-washed five times with $1 \mathrm{ml}$ of $20 \mathrm{mM}$ Tris- $\mathrm{HCl}, \mathrm{pH} 7.5,150 \mathrm{mM} \mathrm{KCl}, 1 \mathrm{mM} \mathrm{MgCl} 2,1$ $\mathrm{mM} \mathrm{CaCl}_{2}, 1 \mathrm{mM}$ DTT, $1 \mathrm{mM}$ PMSF in a $1.5 \mathrm{ml}$ tube, and incubated for another $30 \mathrm{~min}$ with continuous rocking. The beads were collected at the bottom of the tube by pulse centrifugation, and the flow-through was discarded. The beads were washed five times with $1 \mathrm{ml}$ of $20 \mathrm{mM}$ Tris- $\mathrm{HCl}, \mathrm{pH}$ $7.5,150 \mathrm{mM} \mathrm{KCl}, 1 \mathrm{mM} \mathrm{MgCl} 2,1 \mathrm{mM} \mathrm{CaCl} 2,1 \mathrm{mM}$ DTT, $1 \mathrm{mM}$ PMSF, and the retained proteins were eluted with 150 $\mu 1$ of $1 \times$ Laemmli buffer by boiling at $80^{\circ} \mathrm{C}$ for $5 \mathrm{~min}$. For western blot analysis, $40 \mu$ l of the eluates in parallel with the corresponding cleared lysate, flow-through and wash fractions (equivalent of $1 / 500$ of the starting material) were resolved by $15 \%$ SDS-PAGE followed by western blotting as described above.

For LC-MS/MS analysis, the eluted proteins were precipitated overnight with five volumes of glacial $0.1 \mathrm{M}$ ammonium acetate in $100 \%$ methanol. After centrifugation at $12000 \mathrm{~g}$ at $4{ }^{\circ} \mathrm{C}$ during $15 \mathrm{~min}$, the resulting pellets were washed twice with $0.1 \mathrm{M}$ ammonium acetate in $80 \%$ methanol and dried under vacuum (Genevac centrifugation concentrator miVac Duo, Fisher Scientific). The pellets were resuspended in $100 \mu \mathrm{l}$ of $50 \mathrm{mM}$ ammonium bicarbonate and submitted to reduction $(5 \mathrm{mM}$ dithiothreitol, $\left.95^{\circ} \mathrm{C}, 10 \mathrm{~min}\right)$ and alkylation $(10 \mathrm{mM}$ iodoacetamide, room temperature, $20 \mathrm{~min}$ ). Proteins were finally digested overnight with $200 \mathrm{ng}$ of sequencing grade trypsin (Promega). Samples were analysed with nanoLCMS/MS on either a TripleTOF 5600 mass spectrometer (SCIEX) coupled to a NanoLC-Ultra-2D-Plus system (Eksigent), as described previously (47) or on a Q-Exactive Plus mass spectrometer (Thermo Fisher Scientific) coupled to an EASY-nanoLC-1000 chromatograph (Thermo Fisher Scientific) as described previously (48). Each sample was separated on an analytical Acclaim PepMap 100 C18 LC column, $3 \mu \mathrm{m}, 250 \mathrm{~mm}$ length, $0.075 \mathrm{~mm}$ I.D. (Thermo Fisher Scientific) with a $160 \mathrm{~min} 300 \mathrm{nl} / \mathrm{min}$ gradient of acetonitrile. MS data were searched against the $H$. sapiens Swissprot database with a target-decoy strategy (Swissprot release 2019_07; 20432 protein sequences). Peptides and 
proteins were identified with the Mascot algorithm (Matrix Science) and data were further imported into Proline (ProFI Proteomics, http://proline.profiproteomics.fr/). Proteins were validated on Mascot pretty rank equal to 1 , and $1 \%$ FDR on both peptide spectrum matches (PSM score) and protein sets (Protein Set score). Proline was used to align the spectral count values across all samples using the 'Compare with SC' tool. The total number of MS/MS fragmentation spectra was used to quantify each protein.

Overall, 5233 peptides (from 708 proteins), 3802 peptides (from 532 proteins), 13620 peptides (from 895 proteins) and 4353 peptides (from 567 proteins) were identified in the control \#1, control \#2, YBEY-3 $\times$ FLAG coIP \#1, and YBEY$3 \times$ FLAG \#2 samples, respectively. To establish the list of YBEY-3 $\times$ FLAG-associated candidate proteins, highly variable and ambiguous proteins were first filtered. Then the number of spectral counts for each protein was normalized by the total number of spectral counts in the sample, and ratios YBEY-3 $\times$ FLAG coIP/control coIP were taken. Proteins enriched above two medians of these ratios were retained. Poisson 99\% confidence intervals for YBEY$3 \times$ FLAG coIP spectral counts were built with the help of GraphPad QuickCalcs, and the proteins for which the 99\% CI did not include the negative control value were retained. The list of proteins reproducibly enriched in both experiments according to these criteria was further filtered with additional YBEY coIPs to remove likely false positives. The remaining proteins were declared candidate YBEY binders (Supplementary Table S6).

Spectral abundance factors (SAF) for YBEY and p32 were calculated as described in (49) by normalizing the number of the spectral counts by the length of the mature protein (in amino acids). The ratio between the two SAFs provides an estimate for the YBEY:p32 stoichiometry.

The experiment shown on Supplementary Figure S8B was carried out largely in the same way, with the following alterations. As biological material, $1800 \mathrm{~cm}^{2}$ of FlpIn T-REx 293 cells were used to isolate crude mitochondria. The mitochondria were lysed as above in $1 \mathrm{ml}$ of 20 $\mathrm{mM}$ Tris- $\mathrm{HCl}, \mathrm{pH} 7.5,150 \mathrm{mM} \mathrm{KCl}, 1 \mathrm{mM} \mathrm{MgCl} 2,1 \mathrm{mM}$ $\mathrm{CaCl}_{2}, 1 \mathrm{mM}$ DTT, $0.5 \%$-dodecyl- $\beta$-D-maltoside, $1 \mathrm{mM}$ PMSF, and the cleared lysate was split in two $0.5 \mathrm{ml}$ portions. One portion was mixed with $50 \mu 1$ of the $\alpha$-p32 antibody (Santa Cruz Biotechnology, Cat\#sc-271200), whereas the other was treated with $50 \mu$ l of the $\alpha$-FLAG antibody, which in this case served as negative control.

The experiment shown on Supplementary Figure S8A was performed as follows. We first established four parallel cell cultures of $225 \mathrm{~cm}^{2}$ each. The first one was the parental Flp-In T-REx 293 cell line transfected with the empty pcDNA5 FRT/TO plasmid, the second - the same cell line transfected with pSAP0033 to overexpress p32HA, the third - the SAL001 cell line transfected with the empty pcDNA5 FRT/TO plasmid to inducibly overexpress YBEY-3 $\times$ FLAG, the fourth - the same cell line transfected with pSAP0033 to have both YBEY-3 $\times$ FLAG and p32-HA overexpressed. (The pSAP0033 plasmid was obtained by cloning the CIQBP cDNA, amplified with primers SAO00096/SAO00097, into the BspTI/XhoI sites on pcDNA5 FRT/TO.) These cells were grown to $70-80 \%$ confluency and transfected with $22.5 \mu \mathrm{g}$ of the correspond- ing plasmid (mixed with $60 \mu \mathrm{l}$ of Lipofectamine 2000 in 20 $\mathrm{ml}$ OptiMEM containing $0.2 \mu \mathrm{g} / \mathrm{ml}$ tetracycline) for $6 \mathrm{~h}$. The medium was then changed to EMEM and the cells were harvested in $18 \mathrm{~h}$ with ice-cold PBS and directly lysed in 0.5 $\mathrm{ml}$ of $20 \mathrm{mM}$ Tris- $\mathrm{HCl}$, pH 7.5, $150 \mathrm{mM} \mathrm{KCl}, 1 \mathrm{mM} \mathrm{MgCl}$, $1 \mathrm{mM} \mathrm{CaCl} 2,1 \mathrm{mM}$ DTT, $0.5 \%$ n-dodecyl- $\beta$-D-maltoside, $1 \mathrm{mM}$ PMSF. The resulting cleared lysates were split in two portions of $250 \mu$, each mixed with either $10 \mu l$ of the $\alpha$ FLAG antibody or $10 \mu \mathrm{l}$ of the $\alpha$-HA antibody (SigmaAldrich, Cat\#H6908) and incubated for 30 min with constant rocking. Thereafter, the lysates were mixed with 40 $\mu l$ of protein A-sepharose beads, pre-washed as above. The rest of the procedure was the same. The cleared lysate, flowthrough, wash fractions (equivalent of $1 / 125$ of the starting material) and eluates $(20 \mu 1)$ were analysed by $15 \%$ SDSPAGE followed by western blotting.

\section{Purification of proteins from $\boldsymbol{E}$. coli}

YBEY, CIQBP, MRPS11 and MRPL18 cDNAs were obtained by RT-PCR from total RNA (isolated from Flp-In T-REx 293 cells, as described in section 'cRTPCR'). RT-PCRs were performed with the One-step RT-PCR kit by the default manufacturer's protocol with the following primers: SAO00143/SAO00144 (YBEY), SAO00173/SAO00174 (CIQBP), SAO00213/SAO0213 (MRPS11), SAO00161/SAO00163 (MRPL18). The resulting RT-PCR products were digested with corresponding restriction endoribonucleases and used for cloning as follows. $Y B E Y$ was first cloned into pET-21d via the $\mathrm{NcoI}$ and XhoI sites with a C-terminal $\mathrm{His}_{6}$ tag, and the resulting inhibitory short upstream ORF was removed by QuikChange with SAO00153/SAO00154 to derepress the YBEY protein production. The resulting pSAP0077 plasmid conferring resistance to ampicillin was introduced into Rosetta cells to yield the IPTG-inducible SAB0103 strain. The same plasmid served as template to derive YBEY mutant versions by QuikChange with the following primers: SAO00042/SAO00043 (R55A), SAO00056/SAO00057 (R57A), SAO00044/SAO00045 (D62A), SAO00046/SAO00047 (H118A), SAO00048/ SAO00049 (H122A), SAO00050/SAO00051 (H128A), SAO00052/SAO00053 (M137A), SAO00054/SAO00055 (E141A). The resulting plasmids (pSAP0079 through pSAP0086, respectively) were introduced in Rosetta cells to yield the SAB0116 through SAB0123 strains.

$C 1 Q B P$ (mature form) was cloned into pET-30a via the NdeI and XhoI sites without any tag. The resulting pSAP0097 plasmid conferring resistance to kanamycin was introduced into Rosetta cells to yield the IPTG-inducible SAB0144 strain. The SAB0146 strain, containing both pSAP0077 and pSAP0097 and, therefore, inducibly cooverexpressing both $\mathrm{YBEY}^{-\mathrm{His}_{6}}$ and $\mathrm{p} 32$, was constructed by transforming SAB0144 with pSAP0077.

MRPS11 (mature form) was first cloned into $\mathrm{pET}-30 \mathrm{a}$ via the NdeI and XhoI sites with a C-terminal $\mathrm{His}_{6}$ tag, which was removed by QuikChange with SAO00221/SAO00222 primers. The resulting pSAP0112 plasmid conferring resistance to kanamycin was introduced into Rosetta cells to yield the IPTG-inducible SAB0199 strain. 
MRPL18 (mature form) was cloned into pET-15b via the NdeI and BamHI sites with an N-terminal $\mathrm{His}_{6}$ tag, and the ORF was corrected by QuikChange with SAO00064/SAO00065 primers. The resulting pSAP0007 plasmid conferring resistance to ampicillin was introduced into BL21 Star (DE3) cells to yield the IPTG-inducible SAB0021 strain. The identities of all inserts were verified by Sanger sequencing.

To purify YBEY-His 6 variants or $\mathrm{His}_{6}-\mathrm{uL} 18 \mathrm{~m}$ under denaturing conditions, the SAB0103/ SAB0116-SAB0123 or SAB0021 strains, respectively, were grown standardly overnight in the $\mathrm{LB}$ medium at $37^{\circ} \mathrm{C}$ in the presence of 100 $\mu \mathrm{g} / \mathrm{ml}$ ampicillin and $34 \mu \mathrm{g} / \mathrm{ml}$ chloramphenicol. The resulting culture was inoculated 1:100 in $10 \mathrm{ml}$ of fresh LB medium with the same antibiotics and grown at $37^{\circ} \mathrm{C}$ at constant shaking until $\mathrm{OD}_{600}$ of $0.5-0.8$. Then $0.1-0.2 \mathrm{mM}$ IPTG was added to induce protein production, the culture was shifted to $30^{\circ} \mathrm{C}$ and grown for another $4 \mathrm{~h}$. The induced culture was rapidly cooled down on ice for $10 \mathrm{~min}$ and harvested by centrifugation at $4000 \mathrm{~g}$ for $10 \mathrm{~min}$ at $4^{\circ} \mathrm{C}$. The cell pellet was washed thrice with ice-cold $50 \mathrm{mM}$ Tris$\mathrm{HCl}, \mathrm{pH} 8,150 \mathrm{mM} \mathrm{KCl}$. The pellet was resuspended in $500 \mu \mathrm{l}$ of denaturing lysis buffer $(50 \mathrm{mM}$ Tris- $\mathrm{HCl}, \mathrm{pH} 8$, $500 \mathrm{mM} \mathrm{KCl}, 8 \mathrm{M}$ urea) at room temperature and sonicated until the solution became clear. The lysate was cleared by centrifugation at $14000 \mathrm{~g}$ for $10 \mathrm{~min}$ at room temperature. The cleared lysate was loaded on $100 \mu 1$ of Ni-NTA agarose beads (QIAGEN), pre-washed twice with $1 \mathrm{ml}$ of denaturing washing buffer $(50 \mathrm{mM}$ Tris- $\mathrm{HCl}, \mathrm{pH} 7.5,500 \mathrm{mM}$ $\mathrm{KCl}, 1 \mathrm{mM} \mathrm{MgCl} 2,20 \mathrm{mM}$ imidazole, $8 \mathrm{M}$ urea), and incubated with constant rocking for $1-2 \mathrm{~h}$ at room temperature. The beads were sedimented by pulse centrifugation and the flow-through was discarded. The beads were washed twice with $1 \mathrm{ml}$ of denaturing washing buffer at room temperature. Snap renaturation was performed by triple washing with $1 \mathrm{ml}$ of native washing buffer $(20 \mathrm{mM}$ Tris- $\mathrm{HCl}, \mathrm{pH}$ $7.5,150 \mathrm{mM} \mathrm{KCl}, 1 \mathrm{mM} \mathrm{MgCl} 2,40 \mathrm{mM}$ imidazole, $1 \mathrm{M}$ urea, $0.05 \%$ Triton X-100, $1 \mathrm{mM} \mathrm{PMSF}$ ) at $4{ }^{\circ} \mathrm{C}$. The residual urea in this and the subsequent buffers, insufficient to denature proteins, was found to improve YBEY solubility. Elution was achieved by step-wise addition and removal of $250 \mu \mathrm{l}$ of elution buffers containing $20 \mathrm{mM}$ Tris- $\mathrm{HCl}, \mathrm{pH}$ $7.5,150 \mathrm{mM} \mathrm{KCl}, 1 \mathrm{mM} \mathrm{MgCl} 2,1 \mathrm{M}$ urea, $0.05 \%$ Triton X100, $1 \mathrm{mM}$ PMSF, and 50, 60, 70, 80, 100, 120, 140, 160 or $180 \mathrm{mM}$ imidazole at $4^{\circ} \mathrm{C}$ ( 5 min per step). Low concentrations of imidazole preferentially remove nonspecifically bound proteins, whereas YBEY-His 6 and $\mathrm{His}_{6}-\mathrm{uL} 18 \mathrm{~m}$ are eluted mostly at $140-160 \mathrm{mM}$ imidazole. These two fractions were typically used for enzymatic assays (see section 'In vitro RNase assays'). The purity of purified proteins was confirmed by SDS-PAGE and LC-MS/MS. The purified proteins were used immediately or stored at $-80^{\circ} \mathrm{C}$ for no more than 1 month (longer storage often results in YBEYHis $_{6}$ aggregation and inactivation). To obtain YBEY filled with $\mathrm{Zn}^{2+}(18)$, induction, lysis, denaturing and renaturing washes were performed in the presence of $0.1 \mathrm{mM} \mathrm{ZnCl}_{2}$.

For protein purification under native conditions from the SAB0103, SAB0144, SAB0146 and SAB0199 strains, $40 \mathrm{ml}$ cultures were grown and induced as above. The pellet of harvested bacteria was resuspended in $500 \mu$ l of ice-cold native lysis buffer (20 mM Tris- $\mathrm{HCl}, \mathrm{pH} 7.5,150 \mathrm{mM} \mathrm{KCl,} 1$
$\mathrm{mM} \mathrm{MgCl}, 1 \mathrm{mM}$ PMSF) and sonicated. The lysate was cleared as above. In the case of the ternary YBEY-His 6 p32-uS11m complex reconstitution, the cleared lysates of the SAB0146 and SAB0199 bacteria were mixed 1:1 and incubated for $30 \mathrm{~min}$ at $4^{\circ} \mathrm{C}$ at constant rocking. The cleared lysate was loaded on $100 \mu 1$ of Ni-NTA agarose beads, prewashed twice with $1 \mathrm{ml}$ of washing buffer $(20 \mathrm{mM}$ Tris- $\mathrm{HCl}$, $\mathrm{pH} 7.5,150 \mathrm{mM} \mathrm{KCl}, 1 \mathrm{mM} \mathrm{MgCl} 2,40 \mathrm{mM}$ imidazole, 1 $\mathrm{mM}$ PMSF), and incubated at constant rocking for $1-2 \mathrm{~h}$ at $4^{\circ} \mathrm{C}$. The beads were sedimented by pulse centrifugation and washed thrice with $1 \mathrm{ml}$ of the ice-cold washing buffer. The proteins were eluted step-wise by addition and removal of $250 \mu \mathrm{l}$ of elution buffers containing $20 \mathrm{mM}$ Tris $-\mathrm{HCl}$, $\mathrm{pH} 7.5,150 \mathrm{mM} \mathrm{KCl}, 1 \mathrm{mM} \mathrm{MgCl} 2,1 \mathrm{mM}$ PMSF, and 50, $60,70,80,100,120,140,160$ or $180 \mathrm{mM}$ imidazole at $4{ }^{\circ} \mathrm{C}$ (5 min per step). Protein concentration was measured by Bradford assay.

\section{In vitro $R$ Nase assays}

The templates for the $12 \mathrm{~S}$ rRNA-mt-tRNA ${ }^{\mathrm{Val}}$ and tRNA $^{\text {Gln }}$ precursor substrates were obtained by PCR with primers SAO00085/HmT7tRNA_Val_R and SAO00149/SAO00150. The corresponding RNAs were produced with the T7 RiboMAX Express large scale RNA production system (Promega) and purified by denaturing PAGE. To perform the cleavage assay, $\sim 50$ ng of RNA per sample were diluted in $10 \mu \mathrm{l}$ of the reaction buffer (50 $\mathrm{mM}$ Tris- $\mathrm{HCl}, \mathrm{pH} 7.5,150 \mathrm{mM} \mathrm{KCl}, 1 \mathrm{mM} \mathrm{MgCl} 2$ ) and rapidly mixed with $5 \mu \mathrm{l}$ of YBEY or $\mathrm{uL} 18 \mathrm{~m}$ solutions, diluted with the corresponding storage buffer (see section 'Purification of proteins from E. coli') to achieve the desired final concentration. The reactions were incubated at $37^{\circ} \mathrm{C}$ for $1 \mathrm{~h}$ (Supplementary Figures $6 \mathrm{C}, \mathrm{D}$ and $7 \mathrm{~A}$ ). Alternatively, $15 \mu l$ samples were systematically retrieved from an accordingly scaled up reaction mixture after indicated times (Supplementary Figure S6E). Then $15 \mu 1$ of denaturing RNA loading buffer $(0.025 \%$ SDS, $18 \mathrm{mM}$ EDTA, $0.025 \%$ bromophenol blue, $0.025 \%$ xylene cyanol in deionized formamide) was immediately added to each sample, and the reaction was stopped by boiling at $95^{\circ} \mathrm{C}$ for $5 \mathrm{~min}$, followed by denaturing 6-8\% $8 \mathrm{M}$ urea PAGE in $1 \times$ TBE and northern blotting with HmT7tRNA_Val_R, SAO00093, or SAO00160 as probes.

\section{High-resolution glycerol gradient analysis}

High-resolution gradient centrifugation was performed as in (50), with modifications to increase resolution, as previously suggested (51). For one gradient, $75 \mathrm{~cm}^{2}$ of cells grown standardly to $80-90 \%$ confluence were harvested and washed with ice-cold $1 \times$ PBS. The cell pellet was resuspended in $0.5 \mathrm{ml}$ of the lysis buffer $(50 \mathrm{mM}$ Tris$\mathrm{HCl}, \mathrm{pH} 7.5,150 \mathrm{mM} \mathrm{KCl}, 20 \mathrm{mM} \mathrm{MgCl}_{2}, 0.5 \% \beta-$ dodecylmaltoside, $1 \mathrm{mM}$ DTT, $1 \mathrm{mM}$ PMSF) and lysed with the help of a Dounce homogeniser (20 strokes). This and the subsequent manipulations were carried out at $4{ }^{\circ} \mathrm{C}$. The lysate was cleared at $14000 \mathrm{~g}$ for $10 \mathrm{~min}$ and loaded on a linear $10-40 \%(\mathrm{w} / \mathrm{v})$ glycerol gradient formed in SW32.1Ti ultracentrifugation tubes (Beckman Coulter) from the light (50 mM Tris- $\mathrm{HCl}, \mathrm{pH} 7.5,150 \mathrm{mM} \mathrm{KCl}, 20 \mathrm{mM} \mathrm{MgCl}{ }_{2}$, 
$0.025 \% \quad \beta$-dodecylmaltoside, $10 \%$ glycerol $(\mathrm{w} / \mathrm{v}), 1 \mathrm{mM}$ DTT, $1 \mathrm{mM}$ PMSF) and heavy (50 mM Tris-HCl, pH 7.5, $150 \mathrm{mM} \mathrm{KCl}, 20 \mathrm{mM} \mathrm{MgCl} 2,0.025 \%$-dodecylmaltoside, 40\% glycerol (w/v), $1 \mathrm{mM}$ DTT, $1 \mathrm{mM}$ PMSF) solutions with the help of the Gradient Master 108 (Biocomp). The gradients were centrifuged for $17 \mathrm{~h}$ on an Optima XPN-100 ultracentrifuge (Beckman Coulter) at $26000 \mathrm{rpm}$ and fractionated in $30 \times 550 \mu \mathrm{l}$ fractions. For protein analysis, 90 $\mu l$ of each fraction was mixed with $30 \mu l$ of $5 \times$ Laemmli buffer. The rest was treated with P:C:I and RNA was reextracted with TRIzol. Proteins were analysed by western blotting. RNA was resolved by denaturing 6\% PAGE and analysed by northern blotting.

\section{LC-MS/MS analysis of mitoribosomes}

Mitochondria were prepared as described in section 'Subcellular and submitochondrial fractionation', with some modifications. 293T-REx cells (three technical replicates) were harvested from $600 \mathrm{~cm}^{2}$ and the three $Y B E Y$ knockout clones from $1200 \mathrm{~cm}^{2}$. Cell pellet was resuspended in $4 \mathrm{ml}$ of chilled RSB buffer and incubated for $15 \mathrm{~min}$ on ice. Cells were homogenized with a small glass douncer. An equal volume of chilled MS buffer was added and the suspension was gently mixed. Nuclei and cell debris were removed and mitochondria pelleted as described above. The mitochondrial pellet was resuspended in $1 \mathrm{ml} \mathrm{RSB} / \mathrm{MS}$ buffers $(1: 1)$, pelleted again, resuspended in $200 \mu$ l of M1 buffer $(600 \mathrm{mM}$ sucrose, 50 mM Tris- $\mathrm{HCl}$, pH 7.6, 1 mM EDTA) and loaded on a sucrose step gradient (1 M sucrose over $1.5 \mathrm{M}$ sucrose in $10 \mathrm{mM}$ Tris- $\mathrm{HCl}, \mathrm{pH}$ 7.6, $1 \mathrm{mM}$ EDTA) formed in a 14 $\times 89 \mathrm{~mm}$ tube (Beckman Coulter). After centrifugation at $20000 \mathrm{~g}$ for $30 \mathrm{~min}$ at $4{ }^{\circ} \mathrm{C}$ on a SW $41 \mathrm{Ti}$ rotor (Beckman Coulter), the mitochondrial interphase was transferred to a fresh tube and an equal amount of $1 \times$ TE buffer was added. Mitochondria were pelleted at $10000 \mathrm{~g}$ at $4^{\circ} \mathrm{C}$ for $6 \mathrm{~min}$ and washed once with chilled M3 buffer supplemented with 1 mM DTT and $0.1 \%$ proteinase inhibitor cocktail. The mitochondrial pellet was resuspended in chilled M3 buffer supplemented with $1 \mathrm{mM}$ DTT, $0.1 \%$ proteinase inhibitor cocktail and $0.02 \%$ digitonin and incubated for $10 \mathrm{~min}$ on ice. The mitochondrial pellet was washed once with chilled M3 buffer supplemented with $1 \mathrm{mM}$ DTT and $0.1 \%$ proteinase inhibitor cocktail and stored at $-80^{\circ} \mathrm{C}$ for further use.

The mitochondrial pellet was dissolved in $200 \mu 1$ of lysis buffer (25 mM HEPES-KOH, pH 7.4, 100 mM KCl, 25 $\mathrm{mM} \mathrm{MgCl} 2,2 \mathrm{mM}$ DTT, $0.01 \%$ proteinase inhibitor cocktail and $1.7 \%$ Triton X-100) and incubated on ice for $15 \mathrm{~min}$. After clearing the lysate by centrifugation at $30000 \mathrm{~g}$ for 20 min at $4{ }^{\circ} \mathrm{C}$, the lysate was loaded on a sucrose cushion $(20$ mM HEPES-KOH, pH 7.4, 100 mM KCl, $20 \mathrm{mM} \mathrm{MgCl}_{2}$, $2 \mathrm{mM}$ DTT, $0.01 \%$ proteinase inhibitor cocktail, $1 \%$ Triton $\mathrm{X}-100,1 \mathrm{M}$ sucrose) in a $11 \times 34 \mathrm{~mm}$ polypropylene tube (Beckman Coulter) and centrifuged for $6 \mathrm{~h}$ at $55000 \mathrm{rpm}$ at $4{ }^{\circ} \mathrm{C}$ on a TLS-55 rotor (Beckman Coulter) in a TL-100 ultracentrifuge (Beckman Coulter). The pellet was dissolved in RapiGest SF (Waters) and the protein concentration was determined (Bio-Rad protein assay, Bio-Rad). The mitoribosomal lysates were frozen in liquid nitrogen and analysed at the Proteomics core facility of the Medical University of Vienna. Sample preparation and measurement were carried out as previously described (52). Briefly, peptides were separated on a C18 $\mu$-Pillar-Arrayed-Column (PharmaFluidics) using the nanoRSLC UltiMate 3000 HPLC system (Thermo Fischer Scientific). The pillars had an interpillar distance of $2.5 \mu \mathrm{m}$ and the separation was performed at a flow rate of $600 \mathrm{nl} / \mathrm{min}$ over a total separation path of $2 \mathrm{~m}$ using a $10 \mathrm{~min}$ isocratic step $(5 \%$ of the following solution: $50 \%$ acetonitryl, $30 \%$ methanol, $10 \%$ 2,2,2-trifluoroethanol, $0.1 \%$ formic acid), followed by increasing amounts of the above-mentioned solution to $20 \%$ until $30 \mathrm{~min}$, and $40 \%$ from $30 \mathrm{~min}$ to $60 \mathrm{~min}$. Columns were flushed with $90 \%$ of the solution for 5 min until $65 \mathrm{~min}$, followed by a column equilibration of $11 \mathrm{~min}$. The measurement was repeated three times for each sample. Blank samples (injection of loading solvent) were run between sample injections for cleaning of the separation system and preventing carry-over. Mass spectrometric detection and MS/MS analysis was performed using the Q-Exactive Orbitrap BioPharma (Thermo Fisher Scientific). Electrospray ionization was achieved by using a voltage of $2 \mathrm{kV}$.

Database search was performed using Proteome Discoverer 2.2 (Thermo Fisher Scientific) with the Swissprot Human Database (version Jan. 2019). Proteins were detected with a Q-Exactive Plus Biopharma mass spectrometer and the data were analysed with Scaffold (v. 4.6.5, Proteome Software). Two missed tryptic cleavages were allowed and the false discovery rate was $1 \%$. For statistical analysis, two or more peptides with individual assignments at 95\% confidence were required.

\section{Protein sequence and structure analysis}

Sequences of the canonical isoforms of the cloned proteins were retrieved from UniProt (https://www.uniprot.org/) and their corresponding cDNA sequences from NCBI Nucleotide (https://www.ncbi.nlm.nih.gov/nucleotide). Predictions of mitochondrial targeting were performed with MitoFates (53), TargetP (54) and Mitoprot (55) with default parameters. Mature forms of YBEY, uL18m and p32 were chosen based on published data $(21,56,57)$. The mature form of uS11m was arbitrarily chosen based on MS data retrieved from neXtProt (https://www.uniprot.org/), further refined with the MTS prediction tools and multiple sequence alignment of bacterial and mitochondrial uS11 orthologues, which were retrieved from InterPro (https:// www.ebi.ac.uk/interpro/beta/), with COBALT (58). Structural model of human YBEY was obtained with RaptorX (59) with default parameters.

All protein and ribosome structures $(60,61)$ were visualized in PyMOL (https://pymol.org/2/). Positionally equivalent YBEY residues for mutagenesis were identified by multiple sequence alignment (COBALT) of YBEY homologues retrieved from InterPro, further confirmed by the RaptorX structural model analysis with PyMOL. pI predictions were performed with the ExPASy: Compute pI/Mw tool (62).

\section{Phylogenetic analyses}

Phyla with at least one genome sequenced with contigs of $>100,000 \mathrm{bp}$ (as retrieved from NCBI Genome, https: //www.ncbi.nlm.nih.gov/genome, in January 2019) were visualized with the help of the Interactive Tree of Life (63). 
YBEY protein sequences were retrieved from InterPro and verified for contamination with NCBI BLAST (64). For apparent YBEY-negative groups, targeted searches were performed in NCBI BLAST with E. coli, human or the closest relative YBEY orthologue as queries. Obtained new hits were verified for the presence of the diagnostic features of the YBEY family (e.g. histidine triad).

\section{Statistical analyses}

Full details of statistical measures, sample sizes, definitions and analyses are provided in figure legends or directly in the corresponding figures. Most of the descriptive statistics in this study, as well as Pearson's correlation measurements, were done in Microsoft Excel 2010 (Microsoft), with the exception of the violin plots on Supplementary Figure S11 created with Microsoft Power BI Desktop (v. 2.71.5523.821). Two-tailed Fisher's exact test was calculated in GraphPad QuickCalcs (GraphPad). KolmogorovSmirnov test was calculated in Physics: Tools for science (College of St Benedict, St John's University; http://www. physics.csbsju.edu/stats/KS-test.n.plot_form.html). In the majority of cases, when $n$ was high, the two-tailed MannWhitney test, free of the assumptions of normality and homoscedasticity, was used to compare groups. For low-tomoderate $n$, when the assumption of normality was met (i.e. qPCR-based data), the two-tailed unpaired Welch's test, free of the assumption of homoscedasticity, was used to compare two means. In few remaining cases with $n=$ 3 and homoscedastic normal data, for the sake of higher power, the one- or two-sample unpaired two-tailed $t$-test was applied. All these tests and the corresponding assumptions were implemented with the help of Statistics Calculators (Statistics Kingdom; http://www.statskingdom.com/ index.html). Power and sample size calculations were performed in Power and Sample Size (HyLown Consulting LLC; http://powerandsamplesize.com/). Adjustments for multiple comparisons following the Benjamini-Hochberg or Bonferroni procedures were performed as described in (65).

\section{RESULTS}

\section{Human YBEY is a mitochondrial protein}

Uncertainty exists with regard to the subcellular localization of human YBEY. One high-throughput study reported it as a nuclear (66) and another one as a mitochondrial protein (22). However, algorithms like MitoFates, TargetP and Mitoprot consistently predict an N-terminal mitochondrial targeting sequence (Figure 1A) $(53,55,67)$. Indeed, subcellular fractionation revealed the presence of the protein in the mitochondrial but not in the nuclear fraction (Figure 1B). We also tagged the protein on its $\mathrm{C}$-terminus with the FLAG epitope and tracked the protein by immunostaining in transiently or stably transfected human cells (Figure 1C, Supplementary Figure S2). The protein colocalized with the mitochondrial marker TOMM20 in all studied cell types, without evidence for an additional nuclear localization. Moreover, high-resolution confocal microscopy analysis suggested that YBEY localises in the inner compartment of mitochondria, since its signal was maximal in the middle of the organelle, while it dropped on the periphery, where the outer-membrane protein TOMM20 is found (Figure 1C, D). We performed submitochondrial fractionation of isolated organelles by subjecting them to hypotonic swelling to disrupt the outer membrane or to full lysis to destroy both mitochondrial membranes. Upon proteinase $\mathrm{K}$ treatment of intact or swollen mitochondria, YBEY remained resistant to digestion and only disappeared when the mitochondria were fully lysed, similarly to the matrix-localized mitoribosomal protein $\mathrm{uL} 4 \mathrm{~m}$. In contrast, the outer membrane protein TOMM20, facing the cytosol, was digested in all analysed samples, whereas the inner membrane protein OPA 1 , which is highly exposed in the intermembrane space, specifically disappeared upon the rupture of the outer membrane; Figure 1E). Altogether, these experiments confirmed that YBEY is a bona fide mitochondrial matrix protein.

\section{YBEY is required for normal mitochondrial morphology and respiration}

To study the cellular function of YBEY, we generated complete CRISPR knockouts of its gene (henceforth YBEY KO) in HEK293T-REx cells (Supplementary Figure S3). Compared to $Y B E Y$-expressing parent cells, $Y B E Y$ KO cells showed a significant growth delay and fast medium acidification in glucose-containing medium and failed to thrive on galactose (requiring respiration), suggesting a mitochondrial phenotype (Figure 2A). To assess the effect of YBEY loss on mitochondria, we first analysed mitochondrial morphology by transmission electron microscopy (Figure 2B, C). Whereas $Y B E Y^{+}$cells had normally shaped mitochondria with multiple cristae, $Y B E Y$ KO mitochondria were significantly enlarged and often misshaped, contained less cristae and presented a wide variety of morphological defects, including internal membrane structures and electron-dense inclusions. Since such morphological abnormalities are usually indicative of mitochondrial dysfunction (68), we assessed the respiration phenotype of YBEY KO cells and observed a dramatic decrease in basal and maximal respiration, as well as ATP production rates (Figure 2D), consistent with a pronounced complex I and IV deficiency (Figure 2E). Altogether, the $Y B E Y$ KO resulted in severe mitochondrial dysfunction and the loss of respiration in human cells.

\section{YBEY is essential for mitochondrial gene expression}

To establish the molecular basis of the observed respiration phenotype, we evaluated the levels of select subunits of respiratory complexes in $Y B E Y \mathrm{KO}$ cells by western blotting (Figure 3A). Whereas some of the nucleus-encoded subunits, like SDHA, remained unchanged, the mitochondrial DNA (mtDNA)-encoded COX2 protein was almost undetectable in $Y B E Y$ KO clones. Similarly, NDUFB8, a nucleus-encoded complex I subunit which assembles at a mid-late stage and depends on the presence of the mtDNAencoded ND5 protein (69), was depleted. In line with these observations, metabolic labelling of mitochondrial translation products revealed a nearly complete inability of $Y B E Y$ KO mitochondria to synthesize mtDNA-encoded polypeptides (Figure 3B). Since mtDNA levels were unaffected by 
A

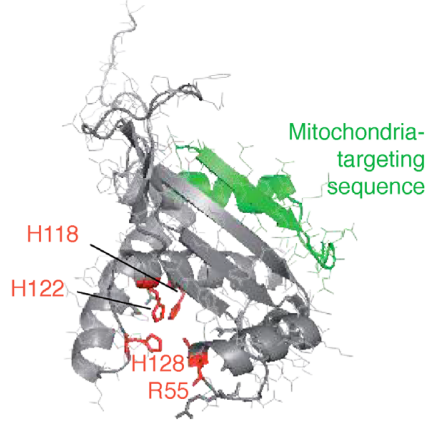

MSLVIRNLQRVIPIRRAPLRSKIEI VRRILGVQKEDLGIICVDNKNIQHI NRIYRDRNVPTDVLSEPEHEHLKAG EFPOPDFPDDYNLGDIFLGVEYIFH QCKENEDYNDVLTVTATHGLCHLIG FTHGTEAEWQQMFQKEKAVLDELGR RTGTRLQPLTRGLFGGS

B

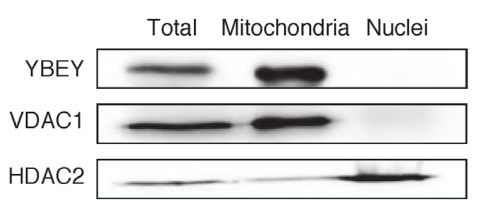

E

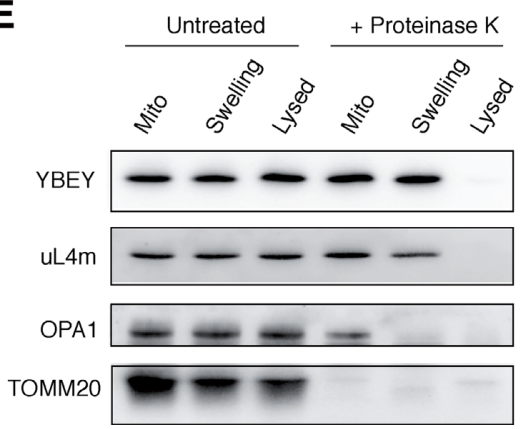

C

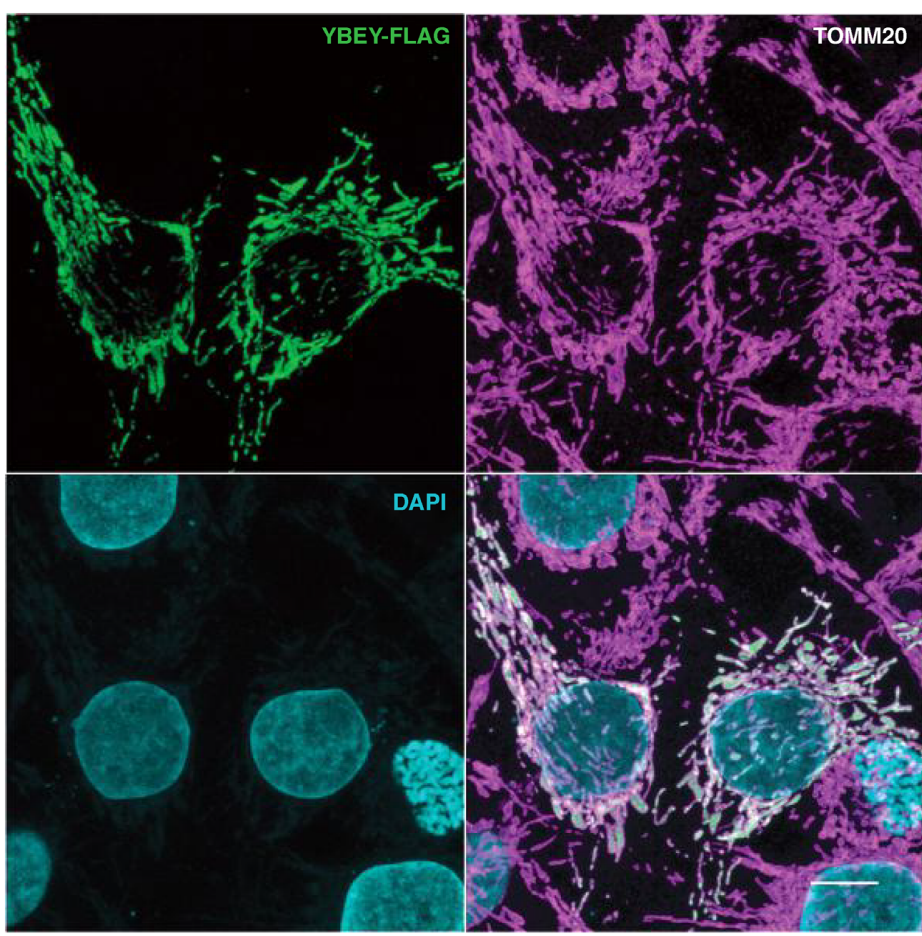

D

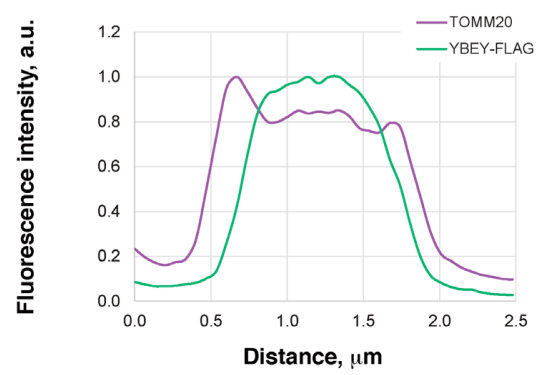

Figure 1. Human YBEY is a bona fide mitochondrial protein. (A) The structural model (RaptorX) and the sequence of human YBEY. The predicted mitochondria-targeting peptide (TargetP) is highlighted in green. The diagnostic histidine triad of the UPF0054 family and the highly conserved R55 residue, mutated in this study, are shown in red. (B) Subcellular fractionation of HEK293T-REx cells supports a mitochondrial localization of endogenous YBEY. VDAC1 and HDAC2 are a mitochondrial and a nuclear marker, respectively. (C) Immunostaining of transiently transfected HepG2 cells expressing YBEY-FLAG. TOMM20 is used as mitochondrial marker. Scale bar, $10 \mu \mathrm{m}$. (D) Representative fluorescence intensity profiles of TOMM20 and YBEYFLAG across a mitochondrion, derived from the experiment shown in (C), indicate the accumulation of YBEY in the interior space of mitochondria. (E) Submitochondrial localization of the YBEY-3 $\times$ FLAG protein. Crude mitochondria ('Mito'), or mitochondria with the outer membrane ruptured by hypotonic swelling ('Swelling'), or mitochondria lysed with $0.5 \% \beta$-dodecyl maltoside ('Lysed') were treated (or not) with proteinase K and analysed by western blotting.

the YBEY loss (Supplementary Figure S4A), this general lack of mitochondrial protein synthesis must have been caused by a mitochondrial gene expression defect.

We next analysed the mitochondrial transcriptome of $Y B E Y$ KO cells (Supplementary Table S5). Similarly to what had been observed in bacteria $(6,9,10,12)$, the YBEY loss in human cells was associated with pervasive changes in mitochondrial RNAs (Figure 3C). Whereas some noncoding antisense RNAs produced from the L-strand appeared upregulated, levels of five mRNAs encoded on the $\mathrm{H}$-strand (including $\mathrm{MT}$ - $\mathrm{CO} 1$ and $\mathrm{MT}$ - $\mathrm{CO} 2$ specifying the COX1 and COX2 proteins, respectively) were significantly decreased in $Y B E Y$ KO cells (Figure 3C, Supplementary Figure S4B). Their downregulation was further corrobo- rated by RT-qPCR and single-molecule FISH (smFISH) (Figure 3D, Supplementary Figure S4C). Since the applied RNA-Seq protocol does not permit to robustly evaluate the levels of mature tRNAs, we measured the expression of select mitochondrial tRNA species of varying abundance and from different genomic contexts by northern blotting and smFISH, but did not find significant differences between the YBEY KO and parental cell lines (Supplementary Figure S4C-E). Altogether, these observations suggest that, while YBEY loss does not seem to affect mitochondrial gene expression at the level of transcription, the expression levels of several transcripts have been perturbed. Since nearly all mammalian mitochondrial RNAs are produced by polycistronic transcription (70), this implicates YBEY, directly 
A

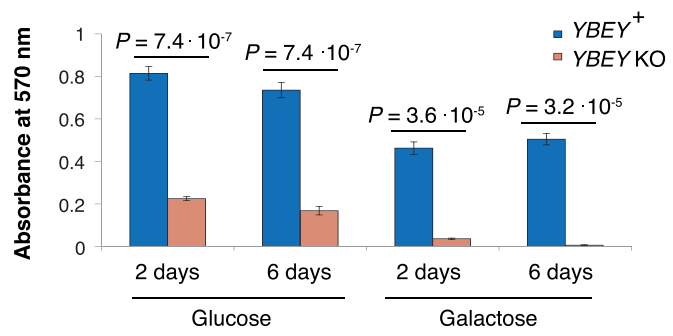

C
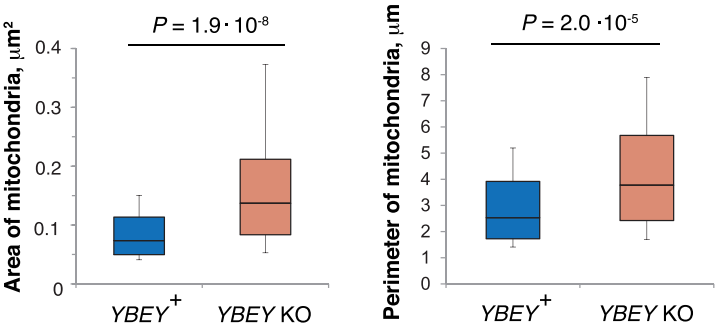

B
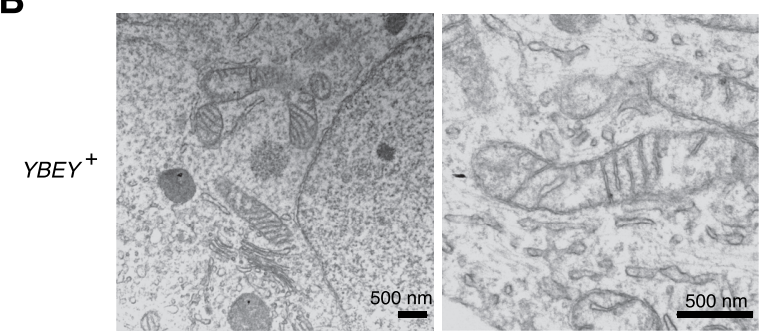

YBEYKO
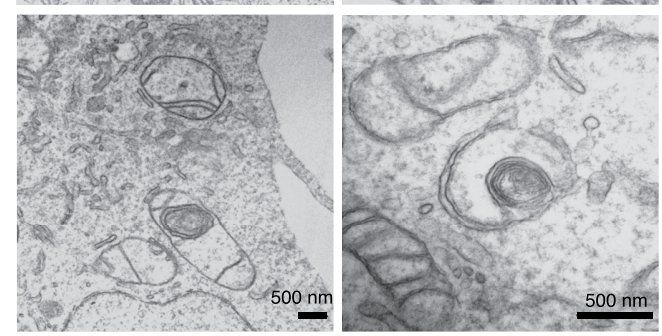

D
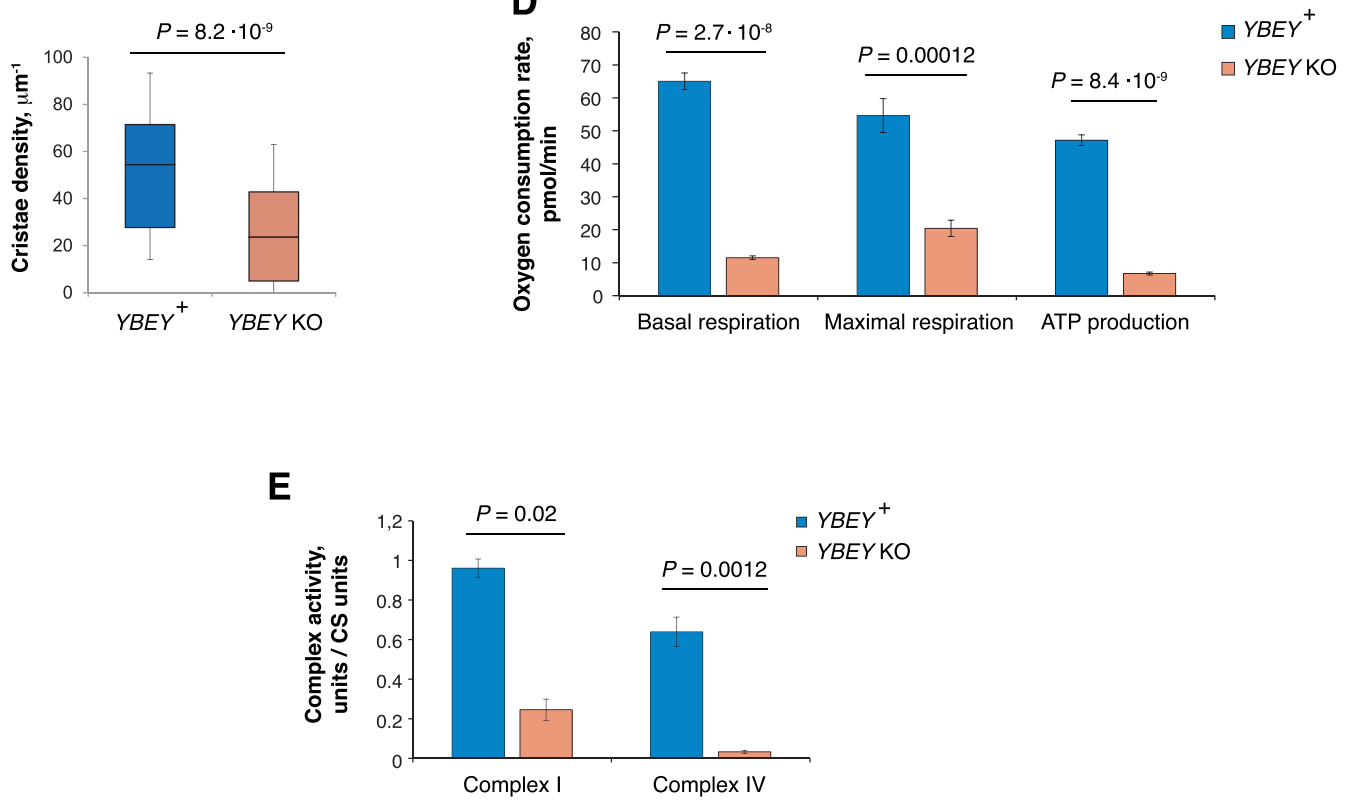

Figure 2. YBEY is required for normal mitochondrial morphology and respiration. (A) MTT assay for cell proliferation reveals a slower growth of $Y B E Y$ $\mathrm{KO}$ cells in a glucose-containing medium and nearly no growth when galactose is used as carbon source. Means \pm SEM for $n=12$ are shown; $P$-values, two-tailed Mann-Whitney test. (B) Transmission electron microscopy of HEK293T-REx cells shows enlarged mitochondria with disorganized cristae systems in YBEY KO cells. A group of mitochondria (left) and individual organelles (right) are shown. Scale bars, $500 \mathrm{~nm}$. (C) Quantitative analysis of mitochondrial morphology from images like in (B). Medians, interquartile ranges, $10^{\text {th }}$ and $90^{\text {th }}$ percentiles are shown. For $Y B E Y^{+}$and $Y B E Y$ KO cells, $n=116$ and 88 mitochondria were analysed, respectively; $P$-values, two-tailed Mann-Whitney test. (D) Respiration phenotypes of $Y B E Y$ KO cells, as assessed by oxygen consumption rate measurement with the Seahorse Mito Stress test. Means \pm SEM for $n=8\left(Y B E Y^{+}\right)$and $n=7(Y B E Y$ KO $)$ are shown; $P$-values, two-tailed Welch's test. (E) YBEY loss results in significantly decreased activities of respiratory complexes I and IV. Means \pm SEM $(n=$ 3 ) of citrate synthase (CS)-normalized activities are shown; $P$-values, two-tailed Welch's test. 
A

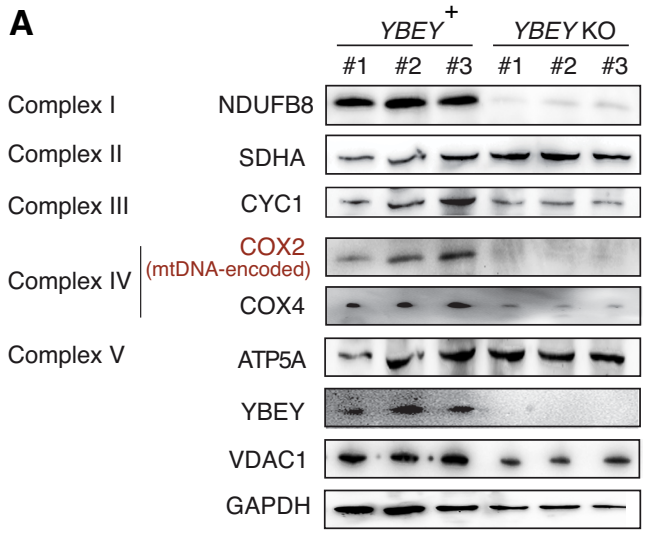

B
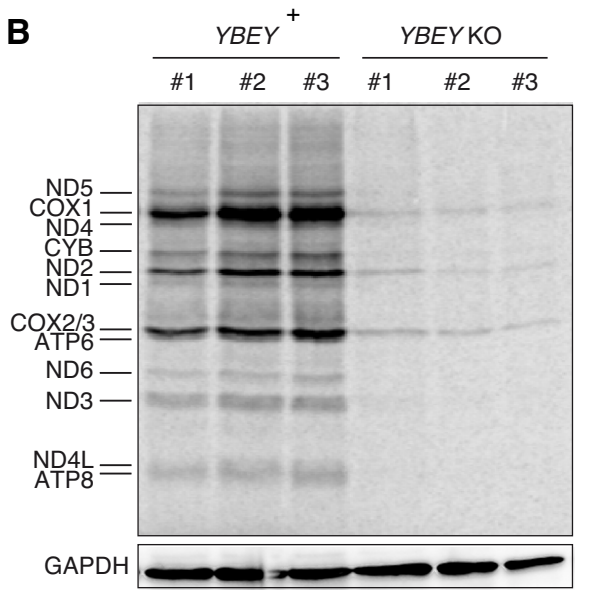

C
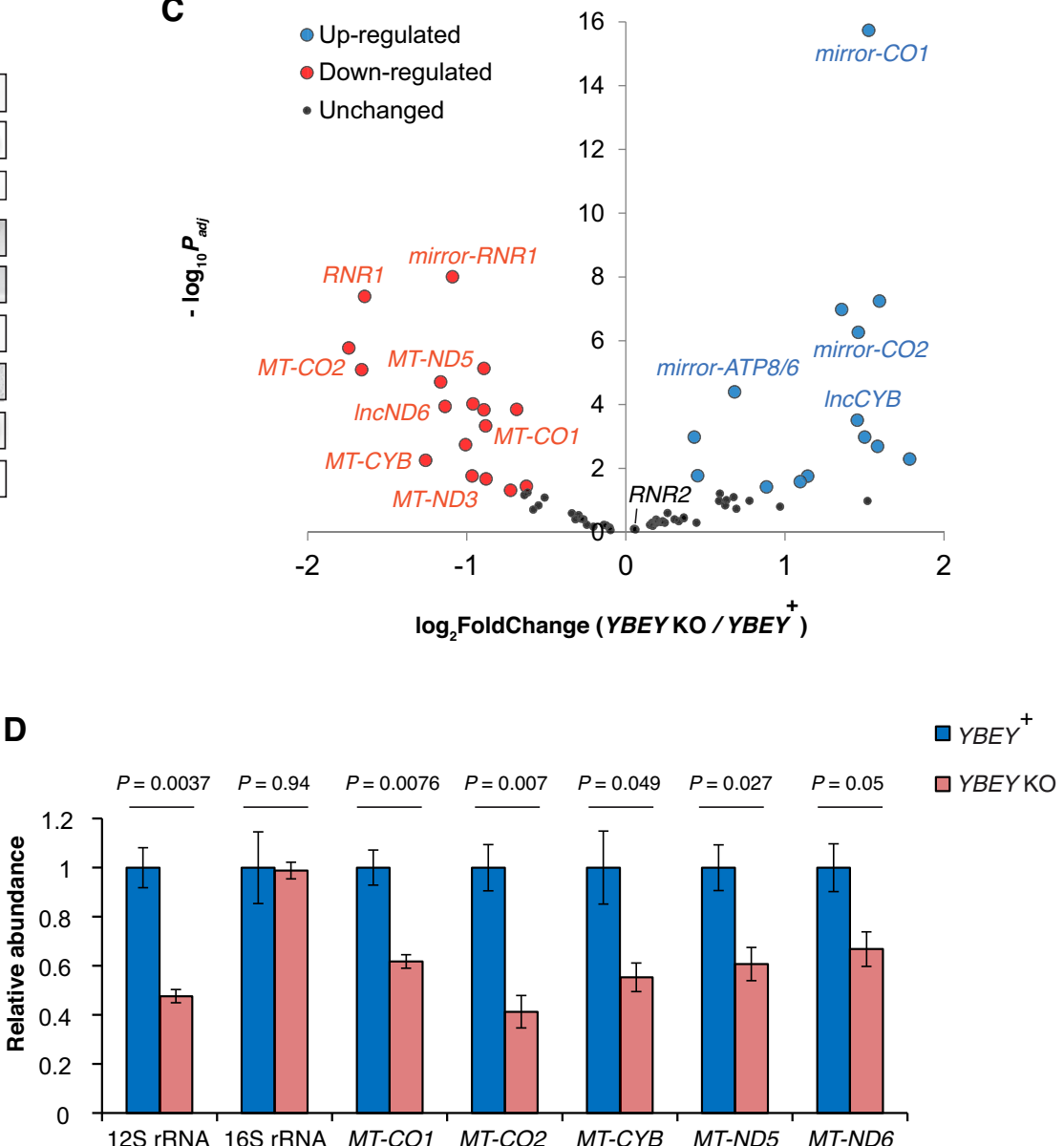

Figure 3. YBEY is essential for mitochondrial gene expression. (A) Western blot analysis of select respiratory chain subunits from $Y B E Y$ KO cells shows selective depletion of the mtDNA-encoded COX2 protein and of the nucleus-encoded NDUFB8 subunit. (All shown proteins, except COX2, are nucleusencoded; VDAC1 and GAPDH are shown as loading controls.) (B) Metabolic [ $\left.{ }^{35} \mathrm{~S}\right]$-methionine labelling of mitochondrial translation products reveals a nearly complete shutdown of protein synthesis in $Y B E Y$ KO mitochondria. (C) Volcano plot summarizing the gene expression changes between $Y B E Y^{+}$ and $Y B E Y$ KO mitochondria as assessed by RNA-Seq. Select loci, further discussed in the text, are highlighted. See also Supplementary Table S5. (D) RT-qPCR measurement of select mitochondrial RNAs in $Y B E Y^{+}$and $Y B E Y$ KO cells. Means \pm SEM for $n=3$ are shown; $P$-values, two-tailed $t$-test.

or indirectly, in post-transcriptional gene expression processes in mitochondria. On the other hand, these deregulations are not sufficient per se to explain the severe general translation phenotype observed in $Y B E Y \mathrm{KO}$ mitochondria (Figure 3B).

\section{YBEY is required to maintain the steady-state level of $12 \mathrm{~S}$} rRNA, but not for rRNA processing

Intriguingly, we observed that the level of $12 \mathrm{~S}$ rRNA (encoded by the $R N R I$ gene) was markedly decreased in $Y B E Y$ $\mathrm{KOs}$, whereas the level of $16 \mathrm{~S}$ rRNA (encoded by $R N R 2$ ) remained unchanged (Figures 3C, D and 4A, Supplementary Figure S4C, D). Moreover, 12S rRNA was significantly less stable in $Y B E Y \mathrm{KO}$ cells, as compared to $Y B E Y^{+}$ (Figure 4B). This molecular phenotype suggests a defect on the mitoribosomal SSU side, reminiscent of what was previously observed in bacteria (3-8). However, as pointed out above, rRNAs in mammalian mitochondria, flanked by tRNA genes without any intervening sequences (Figure $4 \mathrm{~A}$ ), are supposed to require only mitochondrial RNase
$\mathrm{P}$ and RNase $\mathrm{Z}$ for processing (23-25). To directly assess a possible involvement of YBEY in mitochondrial rRNA processing, we directly measured $12 \mathrm{~S}$ rRNA precursor levels by RT-qPCR and mapped the termini of $12 \mathrm{~S}$ rRNAs by RNA-circularization RT-PCR, cloning and sequencing (cRT-PCR). None of the 12S rRNA-precursor ends, and neither the $5^{\prime}$ - nor the $3^{\prime}$-termini of $12 \mathrm{~S}$ rRNA molecules were significantly altered in $Y B E Y$ KOs (Figure 4C, D). In fact, the $Y B E Y^{+}$and $Y B E Y \mathrm{KO}$ cell lines contained slightly (but not significantly) lower $12 \mathrm{~S}$ rRNA precursor levels and virtually indistinguishable populations of correctly processed and polyadenylated $12 \mathrm{~S}$ rRNA molecules (Figure 4E, Supplementary Figure S5A), excluding the involvement of human YBEY in mitochondrial SSU rRNA processing.

Similarly, RT-qPCR did not reveal an accumulation of unprocessed 16S rRNA or tRNA precursors in $Y B E Y$ KO mitochondria (Supplementary Figure S5B,C), and cRTPCR analysis of the MT-CO2 mRNA termini did not uncover any significant defect in its processing or polyadenylation (Supplementary Figure S5D-F). The downregulation 
A

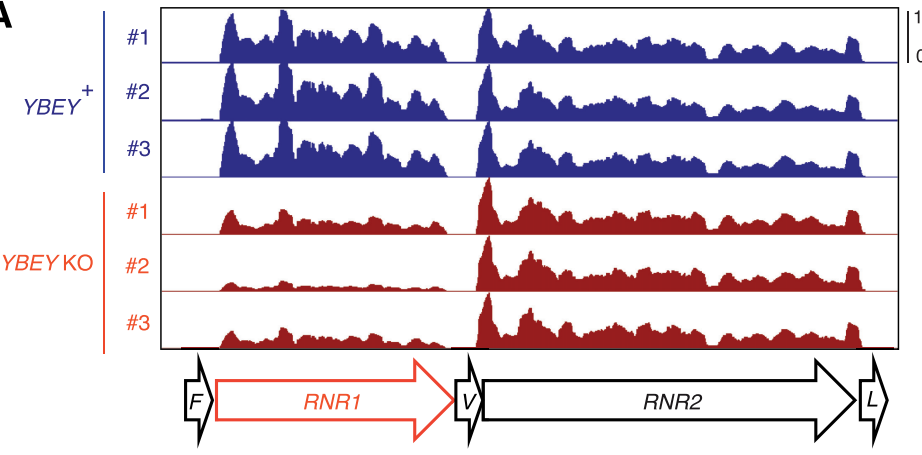

B
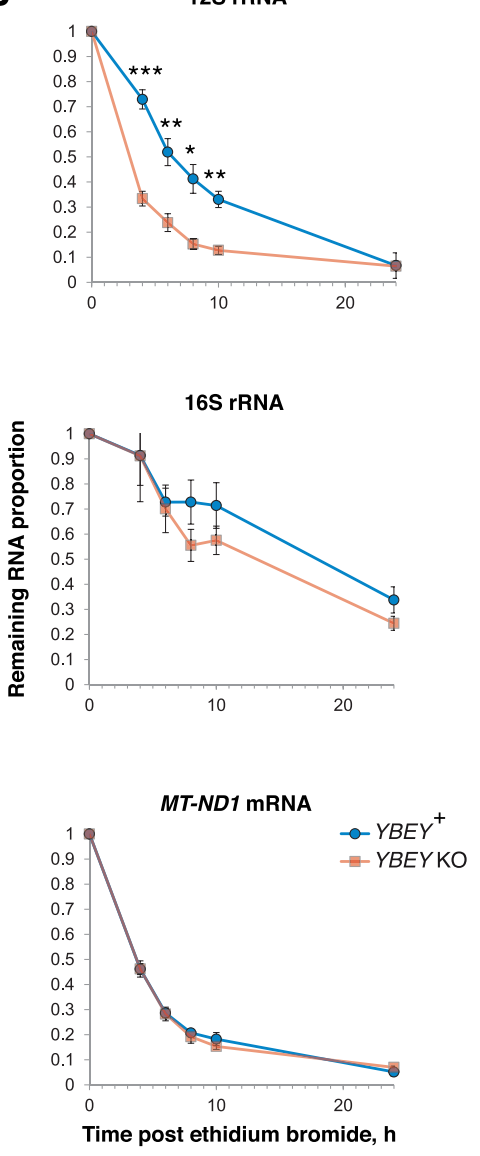

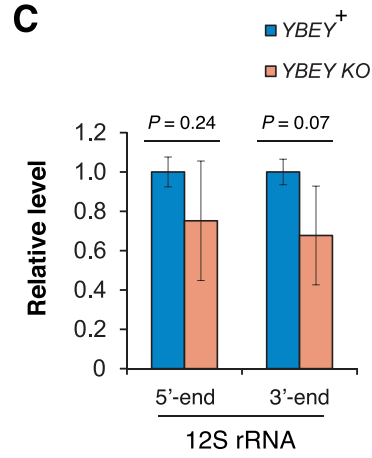

D

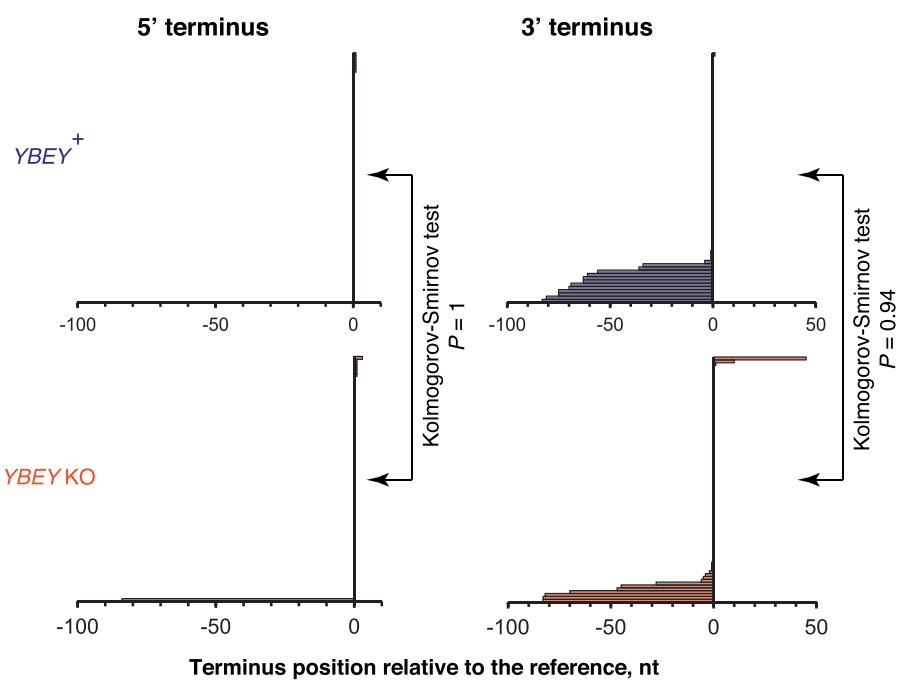

E

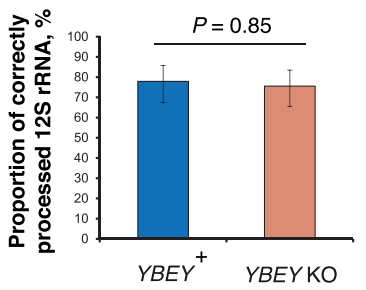

Figure 4. $12 \mathrm{~S}$ rRNA is destabilized, yet correctly processed in the absence of YBEY. (A) Snapshot of the mitochondrial rRNA locus showing a select downregulation of $12 \mathrm{~S}$ rRNA in the absence of YBEY, as assessed by RNA-seq. tRNA genes are labelled with the single-letter code. (B) The half-life of $12 \mathrm{~S}$ rRNA is significantly decreased in $Y B E Y \mathrm{KO}$ cells. RNA samples were collected at various time points after arresting mitochondrial transcription with ethidium bromide and analysed by RT-qPCR. Means \pm SEM for $n=4\left(Y B E Y^{+}\right)$or $n=9(Y B E Y$ KO) are shown; $P$-values, two-tailed Welch's test: $* P=0.013,{ }^{* *} P<0.005,{ }^{* *} P=7.7 \times 10^{-5}$. (C) RT-qPCR analysis of the $12 \mathrm{~S}$ rRNA precursor in $Y B E Y^{+}$and $Y B E Y$ KO cells. The $5^{\prime}$ extension of the primary transcript into tRNA ${ }^{\text {Phe }}$ and the $3^{\prime}$ extension into tRNA ${ }^{\mathrm{Val}}$ were probed by qPCR across the respective junction. Means \pm SEM for $n=3$ are shown; $P$-values, two-tailed $t$-test. (D) cRT-PCR analysis of the $5^{\prime}$ - and $3^{\prime}$-termini of $12 \mathrm{~S}$ rRNA in $Y B E Y^{+}$and $Y B E Y$ KO cells. $n=77$ plasmid clones from two independent $Y B E Y^{+}$cell lines and $n=86$ clones from two independent $Y B E Y$ KO cell lines, represented by horizontal bars, are aligned with respect to the reference positions (a negative number means that the terminus is upstream, a positive - downstream, and ' 0 ' - at the expected reference position). The majority of clones showed correct processing at both ends. (E) $Y B E Y^{+}$and $Y B E Y \mathrm{KO}$ cells have indistinguishable proportions of correctly processed 12S rRNA molecules. Proportions and 95\% CIs are shown; based on the data in (D); $P$-value, Fisher's exact test. 
of select mRNAs observed in $Y B E Y \mathrm{KO}$ cells (Figure 3C, D) may in fact stem from a lack of translation, as previously demonstrated in E. coli (17). Interestingly, mt-16S rRNA, although similarly well processed and polyadenylated in both $Y B E Y^{+}$and $Y B E Y$ KO cells, showed frequent irregular truncations, in particular in the domain I, in the latter background (Supplementary Figure S5G-I). Such 'hidden nicks' may be a result of a subtle destabilization at the level of the large ribosomal subunit (LSU), which finds further support in the analysis of the mitoribosome assembly described below.

\section{Recombinant YBEY has an endoribonuclease activity}

The finding that YBEY KO does not result in detectable misprocessing of $12 \mathrm{~S}$ rRNA (or any other mt-RNA studied) prompted us to evaluate its RNase activity. Recombinant human YBEY-His 6 , purified under denaturing conditions and renatured, showed endoribonuclease activity on the 3'minor domain of $12 \mathrm{~S}$ rRNA fused with tRNA ${ }^{\mathrm{Val}}$, a substrate analogous to the proposed target of bacterial $\mathrm{YbeY}$ at the 3'-end of the SSU rRNA (Supplementary Figure S6AD). However, the primary cleavage site in this substrate was completely off the expected position, truncating the $12 \mathrm{~S}$ rRNA moiety instead of separating it from tRNA ${ }^{\text {val }}$. Moreover, with increasing enzyme concentration the degradation of the substrate proceeded until it was reduced to short oligonucleotides. We observed a similar behaviour on a variety of other RNA substrates (see, for instance, Supplementary Figure S6E), suggesting that on its own YBEY does not site-specifically cleave RNAs but instead, apparently acts as a promiscuous degradative RNase.

To further dissect this RNase activity, we created a series of alanine replacement mutations targeting select conserved residues, some of which have been implicated in catalysis in bacterial YbeY homologues (Figure 1A) $(5,12)$. These mutations affected the RNase activity of human YBEY in vitro to different extents, substitutions H128A and E141A in the active site being more detrimental (Supplementary Figure S7A). We tested the importance of H128 and R55, the latter supposedly involved in RNA binding, for the function of YBEY in human mitochondria by complementing the $Y B E Y \mathrm{KO}$ with stably integrated copies of WT or mutant $Y B E Y$ genes. Surprisingly, not only the WT, but also both tested YBEY variants rescued the $12 \mathrm{~S}$ rRNA depletion and mitochondrial translation phenotypes, and restored cellular respiration (Supplementary Figure S7B-D). Altogether, these data suggest that, although recombinant human YBEY cleaves RNA in vitro, this activity is intrinsically indiscriminate and apparently dispensable for its main role in sustaining mitochondrial translation.

\section{YBEY interacts with $\mathrm{p32}$ and a distinct set of mitoribosomal proteins}

The destabilization of $12 \mathrm{~S}$ rRNA (Figure 4B) in the absence of any apparent RNA processing alterations suggested that rather than rRNA maturation, a later step in the biogenesis of the mitochondrial SSU may be impaired in $Y B E Y \mathrm{KO}$ cells. Therefore, we set out to investigate the protein interactome of human YBEY. To facilitate the detection and the pulldown of the protein, we used an engineered tetracyclineinducible YBEY-3 $\times$ FLAG cell line (Supplementary Figure S2), which only minimally ( $3.2 \pm 0.6$-fold, mean \pm SD) overexpresses the protein, ensuring that the observed interactions are physiologically relevant. Coimmunoprecipitation assays followed by LC-MS/MS identified a reproducible set of enriched YBEY-3 $\times$ FLAG-binding proteins (Supplementary Table S6), which were further confirmed by western blotting (Figure 5A).

One top-scoring YBEY partner was the putative RNAbinding protein $\mathrm{p} 32 / \mathrm{C} 1 \mathrm{QBP}$, critically required for mitochondrial metabolism and associated with a variety of mitochondrial diseases and cancer (71-80). The interaction between the two proteins was confirmed in cross-pulldown assays with the alternate use of YBEY-3 $\times$ FLAG and p32HA proteins as bait and prey (Supplementary Figure S8A). Moreover, pulldown of endogenous p32 selectively enriched endogenous YBEY, excluding any possible effect of tagging or overexpression (Supplementary Figure S8B). Finally, fluorescence lifetime imaging-based Förster resonance energy transfer (FLIM-FRET) confirmed the interaction of the two proteins in intact cells (Figure 5B).

Notably, when YBEY was used as bait, it systematically copurified stoichiometric amounts of $\mathrm{p} 32$ (one-sample $t$-test $P=0.45$ for the $1: 1$ stoichiometry; $P=0.034$ and 0.043 for the 2:1 and 1:2 alternatives, respectively; Supplementary Figure S8C). In contrast, p32, which appears to be a much more abundant protein (22), copurified only small amounts of YBEY. This suggests that whereas YBEY is quantitatively involved in stoichiometric complexes with p32, most of the latter is not associated with YBEY. To further study this interaction, we decided to reconstitute it in a heterologous system of E. coli (Figure 5C, Supplementary Figure S9A). While human YBEY-His 6 alone was insoluble and, therefore, could not be purified under native conditions, native $\mathrm{p} 32$, due to its negative charge ( $\mathrm{p} I 4)$, was fully soluble, but not retained by the Ni-agarose beads due to the lack of a $\mathrm{His}_{6}$ tag. However, when both proteins were coexpressed, a significant proportion of YBEY-His 6 was solubilized and copurified together with p32 in stoichiometric amounts (Figure 5C, Supplementary Figure S9A), in line with our coimmunoprecipitation results. Altogether, these data suggest the existence of a stable and stoichiometric complex of the two proteins.

Most of the other high-scoring proteins copurifying with YBEY were constituents of the mitochondrial ribosome (Figure 5A, Supplementary Table S6). Their specific association with YBEY in intact cells was confirmed by FLIMFRET analysis (Figure 5B); only one of these proteins, $\mathrm{uS} 11 \mathrm{~m}$, is a component of the mitochondrial SSU, whereas the remaining nine LSU proteins all associate with or near domain I of 16S rRNA (Figure 5D). The interaction between YBEY and these mitoribosomal proteins appears to take place outside the mature, fully assembled mitoribosome, since endogenous YBEY formed small and monodisperse complexes and did not associate with ribosomal particles upon glycerol gradient sedimentation (Supplementary Figure S9B). Moreover, it did not interact with other mitoribosomal proteins, such as $\mathrm{mS} 35, \mathrm{mS} 37$ and $\mathrm{mL} 38$ (Figure $5 \mathrm{~A}, \mathrm{~B})$. Given that the vast majority of the YBEYassociated LSU proteins are spatially clustered (Figure 5D) 
A
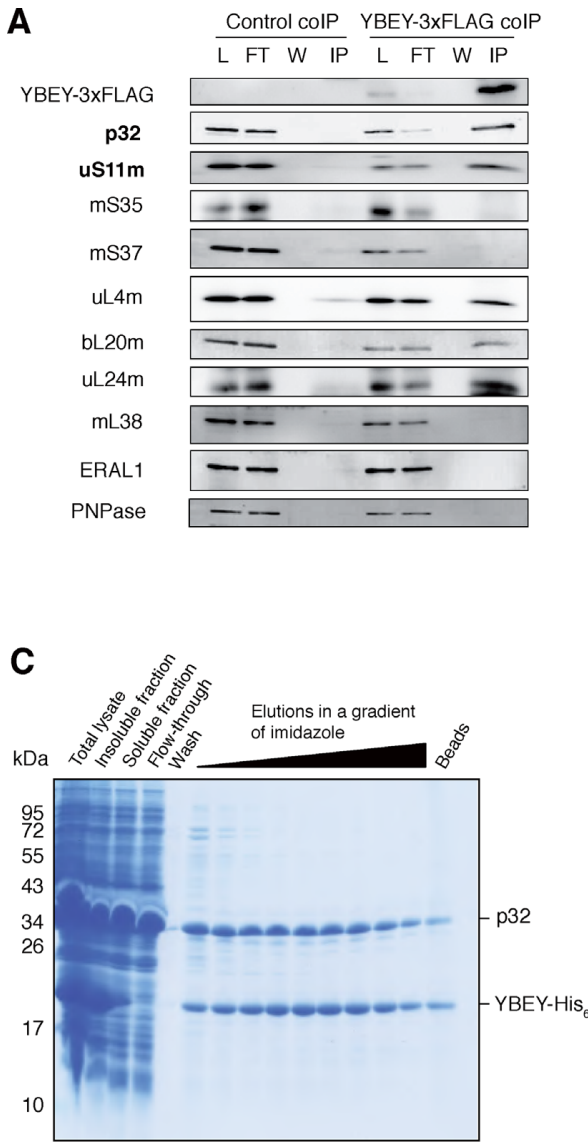

$\mathbf{E}$

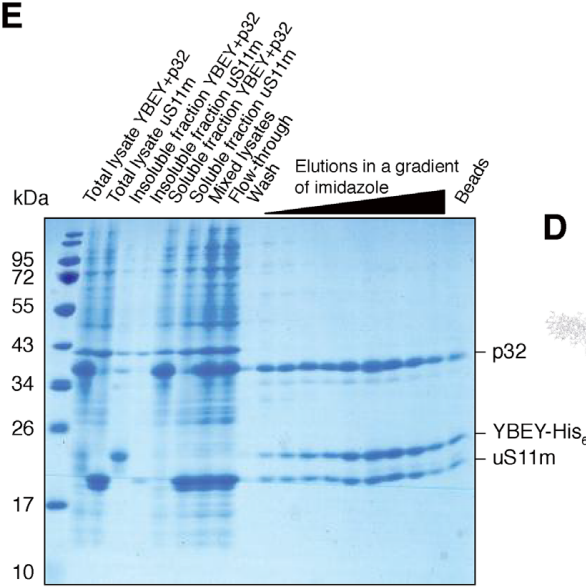

B
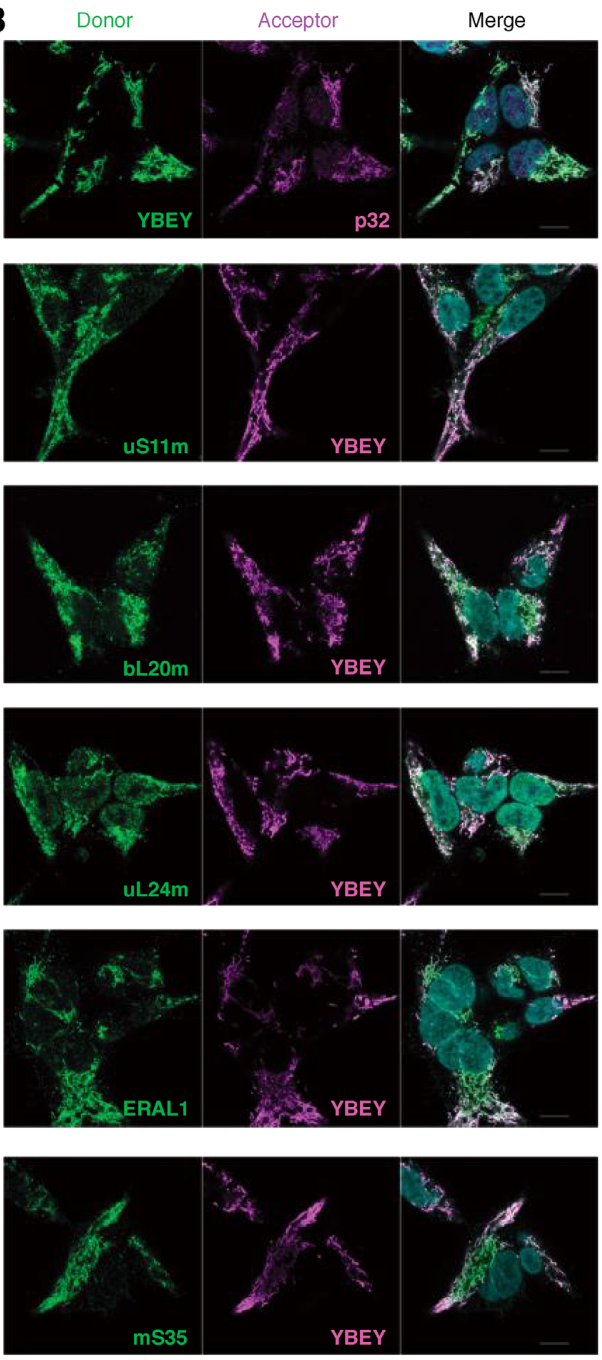
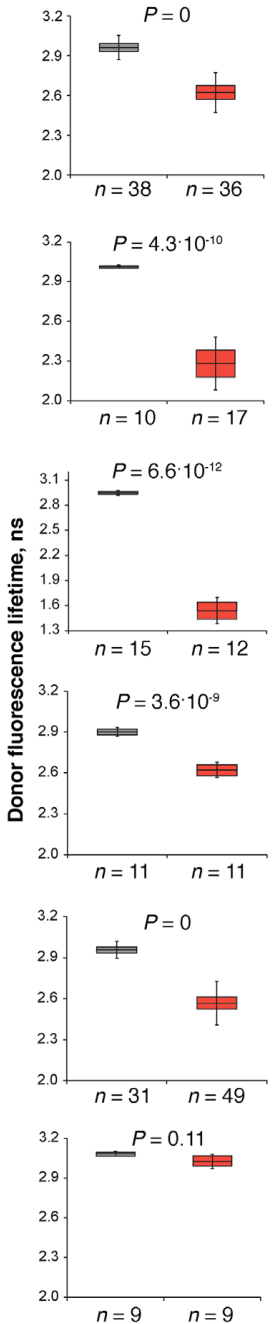

Figure 5. YBEY interacts with $\mathrm{p} 32$ and a distinct set of mitoribosomal proteins. (A) Immunoprecipitation of YBEY-3 $\times$ FLAG from mitochondrial lysates copurifies p32 and select mitoribosomal proteins. Western blot analysis of lysate (L), flow-through (FT), wash (W) and immunoprecipitate (IP) fractions for WT control (not expressing FLAG-tagged baits) and stable YBEY-3 $\times$ FLAG-expressing HEK293T-REx cells is shown. The particularly highly enriched p32 and uS11m proteins are set in bold. See also Supplementary Table S6. (B) Indirect FLIM-FRET analysis of in situ interactions between YBEY and select mitochondrial proteins in HEK293T-REx cells. Representative images of staining of the corresponding partners with fluorescent antibodies forming a FRET couple are shown along with donor fluorescence lifetime measurements when the donor alone (grey boxes) or together with the acceptor (red boxes) is labelled. The boxes show the means and the $95 \% \mathrm{CI}$, the bars are SD. A significant decrease in the donor fluorescence lifetime in the presence of the acceptor (Bonferroni-corrected two-tailed Welch's test) is indicative of FRET between the two and, therefore, of a tight spatial proximity of the interactors. On all microscopy images, the donor is labelled in green and the acceptor in magenta. $\mathrm{mS} 35$ is an example of mitoribosomal protein that does not interact with YBEY. (C) Coexpression of human YBEY-His 6 with tagless $\mathrm{p} 32$ in E. coli results in partial solubilization of the former and stoichiometric copurification of both on a Ni-agarose column. (D) Mapping of the mitoribosomal proteins copurifying with YBEY on the structure of the mammalian mitoribosome. Note the spatial clustering of the enriched LSU proteins around domain I of 16S rRNA. (E) A stable and stoichiometric ternary complex copurifies on Ni-agarose beads from mixed lysates of YBEY-His $6 /$ p32 and uS11m-expressing E. coli cells. See Supplementary Figure S9C for a control purification. 
and recruited at a very early stage of the LSU assembly (8183 ), this interaction may occur at the level of an early LSU assembly intermediate.

As pointed out above, the destabilization of the $12 \mathrm{~S}$ rRNA in YBEY KO suggested a defect on the side of the mitochondrial SSU. Thus, we decided to study the interaction between YBEY and uS1 $1 \mathrm{~m}$ in more detail. Recent studies in E. coli suggested that the function of YbeY may be tightly connected with two SSU-related proteins, uS11 and the ribosome biogenesis GTPase Era $(84,85)$. Although the human Era homologue, ERAL1, was not coimmunoprecipitated with YBEY (Figure 5A), probably due to the GTP dependence of its interactions (86), both $\mathrm{uS} 11 \mathrm{~m}$ and ERAL1 were found to interact with YBEY in situ by FLIM-FRET (Figure 5B). Since no other SSU ribosomal proteins were recovered in our screen, we wondered whether YBEY interacts directly with uS1 $1 \mathrm{~m}$ outside the mitoribosomal context. To directly address this hypothesis, we reconstituted the interaction between recombinant YBEY-His 6 , p32 and uS $11 \mathrm{~m}$ produced in E. coli (Figures 5E, Supplementary Figure S9C). Strikingly, when lysates from bacteria coexpressing YBEY-His ${ }_{6}$ and $\mathrm{p} 32$ on the one side and $\mathrm{uS} 11 \mathrm{~m}$ on the other were coincubated, a stable and stoichiometric complex was formed. These results indicate that YBEY, p32 and uS11m strongly, directly and stoichiometrically interact with each other, raising the question of the functional significance of their association.

\section{YBEY loss results in uS11m-deficient mitoribosomes im- paired in translation}

To evaluate the effect of YBEY on its protein partners, we first analysed their abundance in $Y B E Y^{+}$and $Y B E Y \mathrm{KO}$ cells (Figure 6A). Whereas no significant changes were observed for p32, as well as several LSU proteins and some SSU proteins ( $\mathrm{mS} 27$ and $\mathrm{mS} 35)$, the mitoribosomal protein uS11m was strongly depleted in the $Y B E Y \mathrm{KO}$. This finding was further corroborated by $\mathrm{uS} 11 \mathrm{~m}$ immunostaining in intact $Y B E Y^{+}$and $Y B E Y$ KO cells (Figure 6B). Importantly, uS $11 \mathrm{~m}$ levels were restored by complementation of the $Y B E Y \mathrm{KO}$ with either WT or mutant $Y B E Y$ genes (Figure 6C). Since the MRPS11 mRNA level did not change significantly upon $Y B E Y$ KO (Supplementary Figure S10), we hypothesized that $\mathrm{uS} 11 \mathrm{~m}$ may have been destabilized due to a deficiency in its incorporation into the mitoribosome, as it is frequently the case with other mitochondrial ribosomal proteins $(82,87)$. Indeed, western blot analysis of highresolution glycerol gradients revealed that, although the SSU in $Y B E Y \mathrm{KO}$ mitochondria sedimented similarly to its WT counterpart, it lacked uS11m, which could only be observed in small molecular weight fractions (Figure 6D). In line with this observation, the mitoribosomal protein $\mathrm{mS} 37$ was also strongly depleted in $Y B E Y \mathrm{KO}$ cells (Figure 6A). Together with $\mathrm{bS} 21 \mathrm{~m}, \mathrm{mS} 37$ is an immediate neighbour of $\mathrm{uS} 11 \mathrm{~m}$ in the mitochondrial SSU $(88,89)$, and whereas uS11m directly binds to $12 \mathrm{~S}$ rRNA, the other two proteins structurally depend on uS11m (81), with which they form extensive protein-protein interactions (Figure 6E). Indeed, uS11m knockdown resulted in the same specific $\mathrm{mS} 37$ destabilization as observed in $Y B E Y$ KO cells (Figure 6F), without affecting YBEY levels, thus confirming the hierarchical dependence of $\mathrm{mS} 37$ on uS11m.

To comprehensively evaluate the proteomic composition of the mitoribosomal subunits in $Y B E Y \mathrm{KO}$ cells, we purified them through a sucrose cushion and subjected them to quantitative LC-MS/MS (Figure 6G, Supplementary Table S7). In line with the observed 12S rRNA depletion, levels of the mtSSU proteins were strongly decreased (two-tailed Mann-Whitney test $P=0.0013)$, whereas the overall abundance of mtLSU proteins was not significantly altered $(P=$ 0.79 ). Looking at individual proteins, $7 \mathrm{LSU}$ r-proteins were mildly but significantly depleted, suggesting a slightly perturbed LSU assembly (Figure 6H). This was paralleled by a decreased association of several LSU biogenesis factors, including DDX28 and DHX30 $(90,91)$. In contrast, six SSU proteins were practically absent, including $\mathrm{uS} 11 \mathrm{~m}, \mathrm{bS} 21 \mathrm{~m}$ and several other proteins mostly from the head of SSU (Figure $6 \mathrm{H}$ ). These data confirm the SSU assembly defect in $Y B E Y \mathrm{KO}$ mitochondria suggested by our previous experiments and provide further support to the role of uS11m as a mechanistic link between YBEY and SSU biogenesis.

We wondered whether the depletion of cellular uS $11 \mathrm{~m}$ levels observed in $Y B E Y \mathrm{KO}$ cells was the direct cause of the SSU assembly defect. To this end, we replenished the uS11m pool by mildly overexpressing the protein from a plasmid in $Y B E Y$ KO cells (Figure 6I). Strikingly, whereas re-expression of YBEY-3 $\times$ FLAG in the same cells fully restored the uS11m and $\mathrm{mS} 37$ levels and COX1 production, $\mathrm{uS} 11 \mathrm{~m}$ overexpression failed to rescue mitochondrial translation and, importantly, did not restore the mS37 level. Together with the above results, this finding suggests that YBEY is not a mere $\mathrm{uS} 11 \mathrm{~m}$ stability factor, but is rather actively required for its correct incorporation in the SSU.

$\mathrm{uS} 11 \mathrm{~m}$ and its immediate neighbours bS21m and $\mathrm{mS} 37$ are key constituents of the mRNA exit channel $(88,89)$. Therefore, a lack of these proteins would be expected to result in a translation initiation deficiency, explaining the observed translational shutdown in $Y B E Y$ KO cells (Figure $3 \mathrm{~B}$ ). To assess this possibility, we analysed the association of mt-tRNA ${ }^{\mathrm{Met}}$ and the $M T-N D 3$ mRNA, which form relatively small and clearly distinguishable extraribosomal RNPs, with the mtSSU in high-resolution glycerol gradients (Figure 7A). Whereas in $Y B E Y^{+}$cells a significant proportion of both RNAs cosedimented with the SSU, in $Y B E Y$ KO cells neither RNA was found to be significantly SSUbound (Figure 7A, B), suggesting that $Y B E Y$ KO SSUs are indeed initiation-deficient.

\section{uS11m knockdown phenocopies the $Y B E Y$ KO mitochondrial translation phenotype}

We reasoned that if $Y B E Y \mathrm{KO}$ effects are $\mathrm{uS} 11 \mathrm{~m}$-mediated, $\mathrm{uS} 11 \mathrm{~m}$ knockdown should result in a similar translational phenotype. Indeed, transient RNAi-mediated uS11m depletion with two different siRNA duplexes significantly affected mitochondrial translation in HEK293T-REx cells, and we observed the same loss of mS37 (Figure 7C). Moreover, when we examined the association of mt-tRNA Met and the $M T-N D 3$ mRNA with mtSSU in glycerol gradients, we acknowledged the same loss of mtSSU association as in $Y B E Y \mathrm{KO}$ cells (Figure 7D). Therefore, the 
A

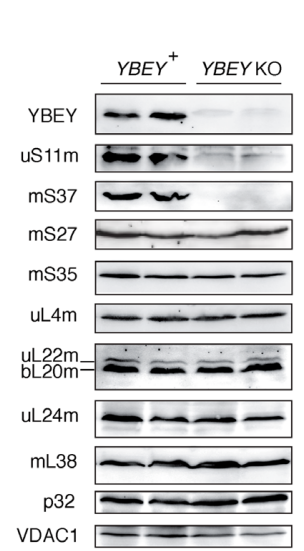

B
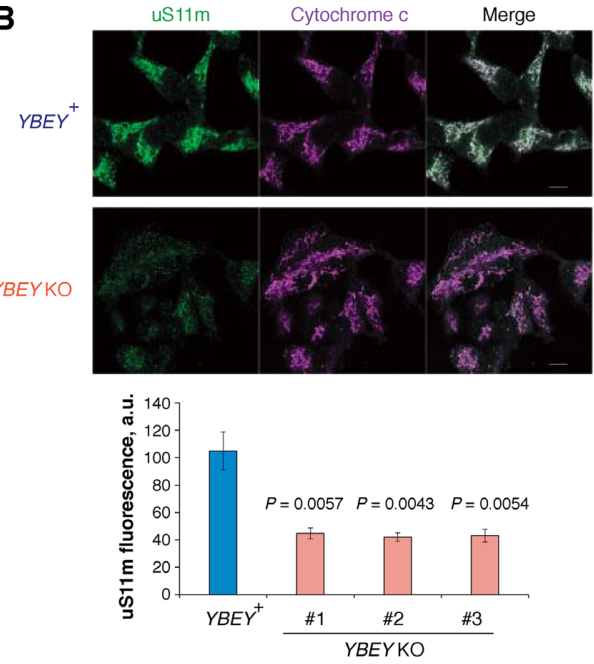

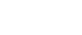

C

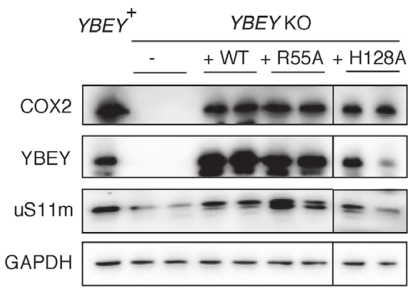

D

YBEY $^{+}$
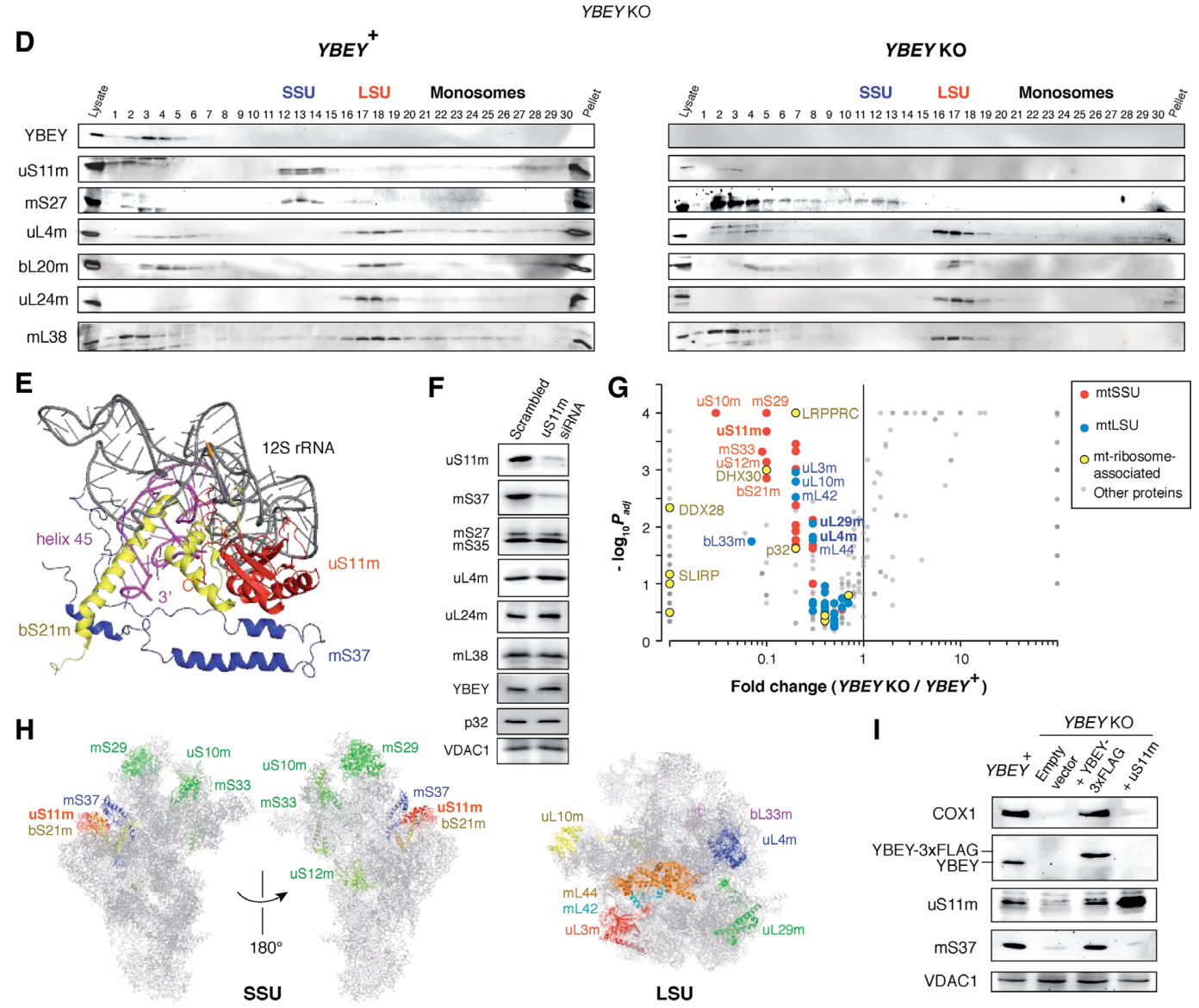

change ( $Y B E Y$

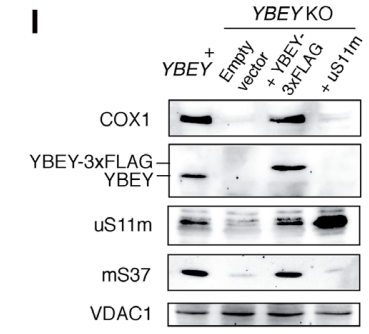

Figure 6. The YBEY loss results in uS11m-deficient mitoribosomes. (A) Western blot analysis of total protein from $Y B E Y^{+}$and $Y B E Y$ KO cells reveals the selective depletion of mitoribosomal proteins $\mathrm{US} 1 \mathrm{~m}$ and $\mathrm{mS} 37$. Two independent cell lines of each genotype are shown. VDAC1 is shown as loading control. (B) Quantitative immunofluorescence analysis of the $\mathrm{uS} 11 \mathrm{~m}$ protein levels in parental $Y B E Y^{+}$and three independent $Y B E Y$ KO cell lines. Cytochrome c is shown as a mitochondrial marker. Means \pm SEM for $n=6\left(Y B E Y^{+}\right.$and $\left.Y B E Y \mathrm{KO} \# 3\right), n=5(Y B E Y \mathrm{KO} \# 1)$, and $n=7(Y B E Y \mathrm{KO} \# 2)$ frames are shown; $P$-values, two-tailed Welch's test. (C) Rescue of uS11m and COX2 levels in $Y B E Y$ KO cells by complementation with WT or mutant $Y B E Y$ genes. Western blotting of total cellular protein is shown; GAPDH is used as loading control. All lanes are cropped from the same membrane. (D) High-resolution 10-40\% glycerol gradient analysis of total $Y B E Y^{+}$and $Y B E Y$ KO cell lysates followed by western blotting reveals the absence of uS1 $1 \mathrm{~m}$ from the mitochondrial SSU in $Y B E Y$ KO cells. (E) The structural context of the uS11m protein in the mammalian mitochondrial SSU (pdb: $3 \mathrm{jd} 5$ ). The primary uS11m-binding site (residues 320-440 of $12 \mathrm{~S}$ rRNA) is shown in grey. The helix 45 contacted by the C-terminal extension of uS1 $1 \mathrm{~m}$ (' $\mathrm{C}$ ') is shown in magenta. Proteins bS $21 \mathrm{~m}$ (yellow) and $\mathrm{mS} 37$ (blue) depend on extensive protein-protein contacts with uS11m and serve to sandwich the $3^{\prime}$-terminus of $12 \mathrm{~S}$ rRNA ( $\left.3^{\prime}\right)$. (F) Transient knockdown of uS11m results in destabilization of mS37. A non-targetting siRNA with a 'scrambled' sequence was used as a control. (G) Quantitative mass spectrometry analysis of the levels of mitoribosomal and copurifying proteins from $Y B E Y$ KO as compared to $Y B E Y^{+}$mitochondria. Particularly strongly downregulated proteins are named. See also Supplementary Table S7. (H) Mapping of the proteins particularly strongly depleted from the mitoribosomes of $Y B E Y$ KO cells on the structure of the mammalian mitoribosome. (I) Transient overexpression of YBEY-3 $\times$ FLAG but not of uS11m in $Y B E Y$ KO cells restores the translation of COX1 and rescues the stability of $\mathrm{mS} 37$. Western blotting of total cellular protein is shown. 
A
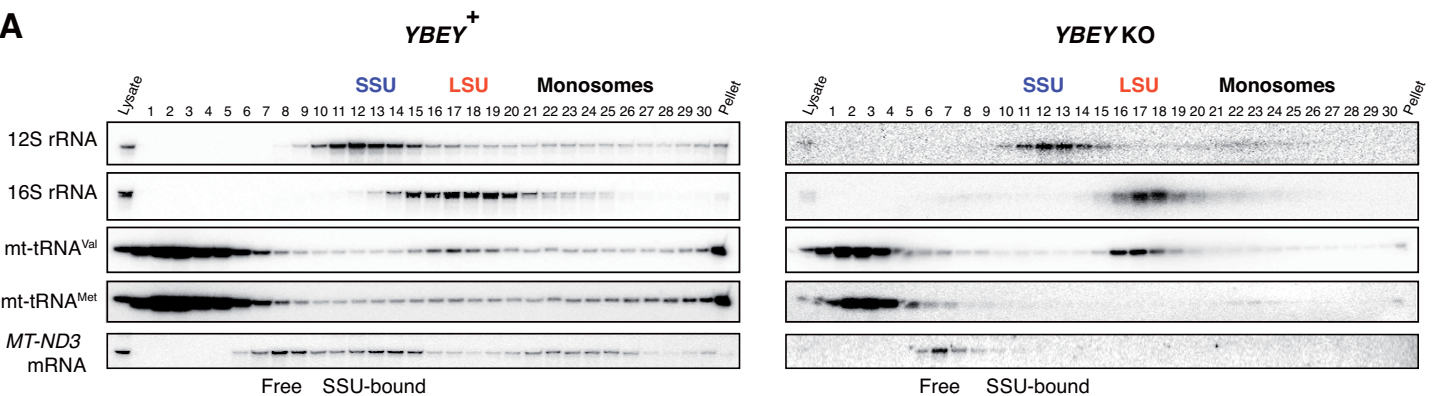

B

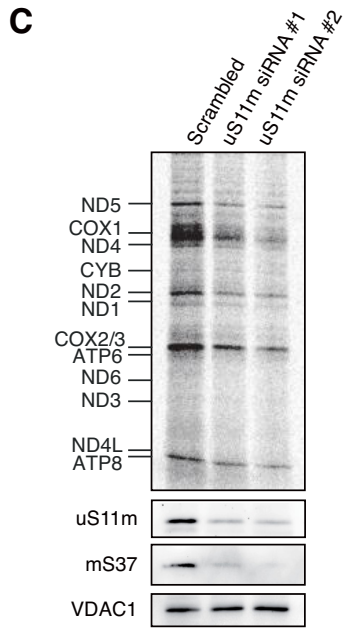

D

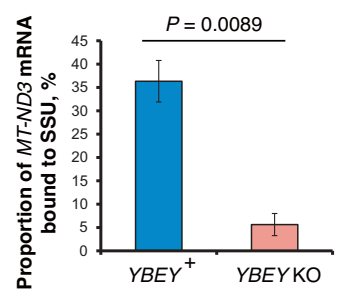

Figure 7. The knockdown of uS11m phenocopies the loss of YBEY. (A) High-resolution 10-40\% glycerol gradient analysis of $Y B E Y^{+}$and $Y B E Y$ KO total cell lysates followed by northern blotting shows a decreased association of the $M T-N D 3$ mRNA and mt-tRNA ${ }^{\text {Met }}$ with the mitochondrial SSU of $Y B E Y$ KO cells. (B) Quantitative analysis of the association of extramitoribosomal MT-ND3 mRNA with the SSU in the $Y B E Y^{+}$and $Y B E Y$ KO cells. Means \pm SEM for $n=3$ independent cell lines are shown; $P$-value, two-tailed Welch's test. (C) Metabolic $\left.{ }^{35} \mathrm{~S}\right]$-methionine labelling of mitochondrial translation products reveals a strong decrease of protein synthesis upon transient uS11m knockdown. A non-targeting control siRNA ('Scrambled') and two different uS11m-directed siRNA duplexes were used for HEK293T-REx cell transfection. The corresponding western blots confirm the uS11m knockdown and the concomitant depletion of mS37. VDAC1 is used as loading control. (D) High-resolution 10-40\% glycerol gradient analysis of the total cell lysates from HEK293T-REx cells transiently transfected with control or uS11m-directed siRNAs followed by northern blotting shows a decreased association of the $M T-N D 3$ mRNA and mt-tRNA ${ }^{\text {Met }}$ with the mitochondrial SSU upon uS11m knockdown.

uS11m knockdown largely phenocopies the $Y B E Y$ knockout, further supporting the role of YBEY in the assembly of initiation-competent mitochondrial SSUs via uS11m.

\section{DISCUSSION}

The deeply conserved YbeY protein has recently come into limelight as a critical factor required for normal physiol- ogy in Bacteria. Its loss has been associated with a wide array of debilitating phenotypes, such as sensitivity to abiotic stresses, inability to establish host-pathogen/symbiont relationships $(6,7,13-15)$, metabolic deregulations and a severe growth impairment up to lethality $(3,11,17)$. Widespread among Eukarya, YbeY has so far only been studied in $A$. thaliana, where it was found indispensable for chloroplast development and photosynthesis (16). Here, we show that 


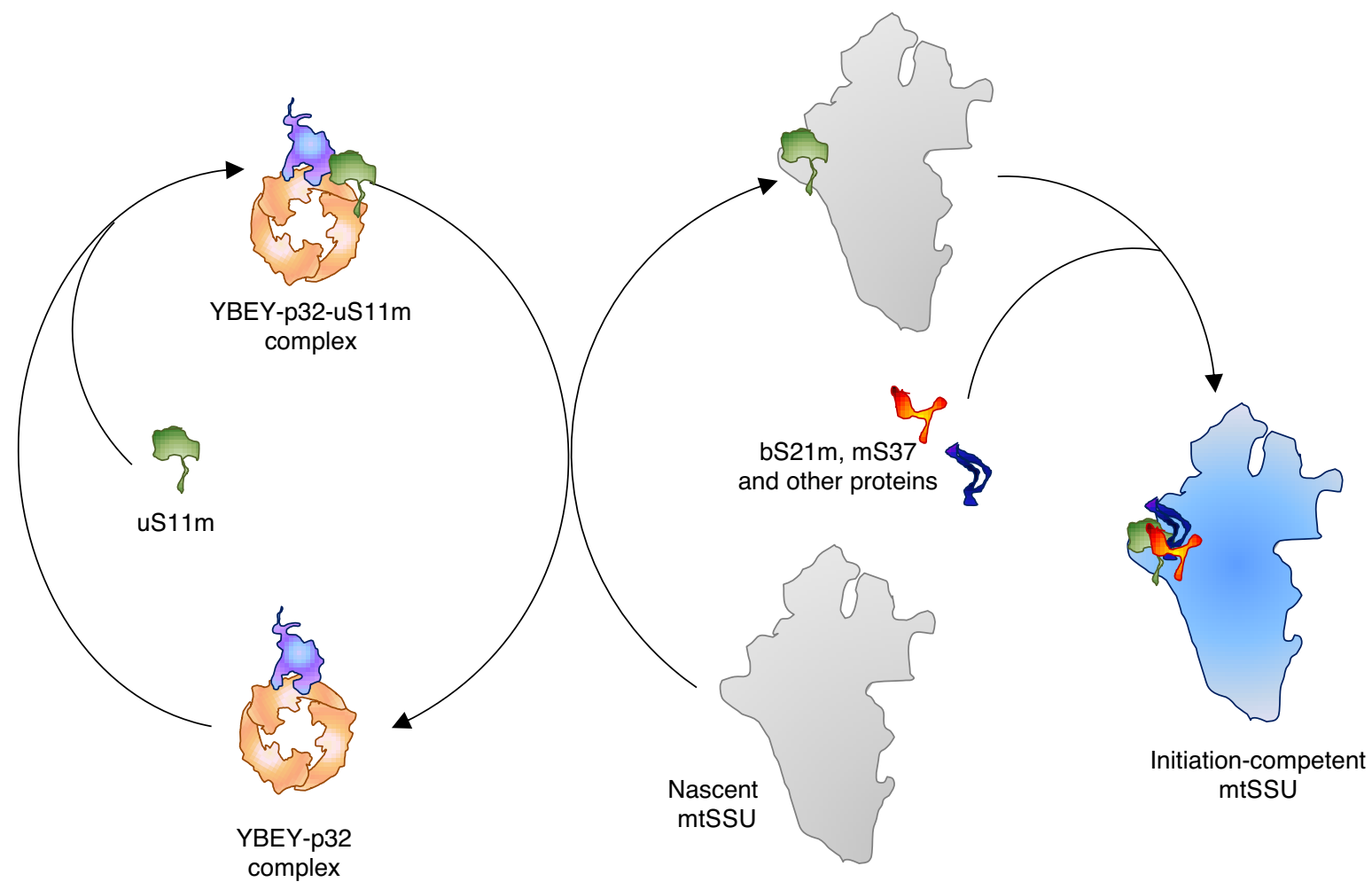

Figure 8. Human YBEY as an assembly factor for the mitochondrial SSU. For clarity, only one YBEY monomer per p32 trimer is shown, albeit our data support a heterohexamer model.

human YBEY localizes to mitochondria and is essential for mitochondrial translation and, consequently, oxidative phosphorylation. We established that the inability of human cells to synthesize mitochondrial polypeptides in the absence of YBEY is apparently the consequence of a mitoribosome assembly defect: the severely destabilized mitochondrial SSU almost completely lacked uS11m and several other ribosomal proteins required for translation initiation. Based on interactome data and functional analyses, we propose that human YBEY, in complex with p32, acts to deliver and/or correctly position $\mathrm{uS} 11 \mathrm{~m}$ on the nascent mitochondrial SSU in order to complete the assembly of an initiation-competent ribosomal particle (Figure 8).

$\mathrm{uS} 11 \mathrm{~m}$ and its immediate neighbours on the mitochondrial SSU play key roles in translation initiation. uS11m, bS $21 \mathrm{~m}$ and $\mathrm{mS} 37$ line the mRNA exit channel $(88,89)$. Additionally, uS11 m makes extensive contacts with mtIF3 (92), predicting that the mtIF3 recruitment to mitoribosomes may be also perturbed in YBEY KO and $\mathrm{uS} 11 \mathrm{~m}$ knockdown cells. The bS21 protein is critically required for translation initiation in bacteria (93), and this function is likely maintained in mitochondria $(88,89)$. Additionally, $\mathrm{mS} 37$ and $\mathrm{bS} 21 \mathrm{~m}$ are strategically positioned to lock the 3'-end of $12 \mathrm{~S}$ rRNA (Figure 6E), which may contribute to its stability and the correct folding of the $3^{\prime}$-minor domain. All these features may explain why $Y B E Y \mathrm{KO}$ and uS11m knockdown cells seem to be deficient in mitochondrial translation initiation (Figure 7). Interestingly, the structural dependence of $\mathrm{mS} 37$ and bS21m incorporation on $\mathrm{uS} 11 \mathrm{~m}$, associated with a considerable rearrangement of the SSU rRNA, has recently been demonstrated in Trypanosoma bruicei (94), suggesting that this assembly hierarchy is conserved in mitochondria across Eukarya. Given the deep conservation of YbeY, uS11, bS21 and Era and their interactions (84) in bacteria and bacteria-derived eukaryotic organelles, it will be important to verify whether the previously reported $\Delta y b e Y$ translation phenotypes can be traced back to a similar SSU assembly defect, and especially the uS11 deficiency, as in human mitochondria.

$Y B E Y \mathrm{KO}$ mitochondrial SSU was found to lack several other functionally important proteins (Figure $6 \mathrm{H}$ ) that are structurally connected with the uS11m-bS21m-mS37 module. $\mathrm{mS} 29 / \mathrm{DAP} 3$ contacts $\mathrm{mS} 37$ via uS7m and plays a major structural role by forming the mitochondria-specific intersubunit bridges $\mathrm{mB} 1 \mathrm{a}$ and $\mathrm{mB} 1 \mathrm{~b}(88)$. uS10m and $\mathrm{mS} 33$ form another structural module which is incorporated late during assembly and was proposed to hierarchically depend on the uS7/mS29-containing cluster (81). Interestingly, $\mathrm{mS} 29$ and uS10m were found to crosslink with mtIF3 (95), again suggesting that $Y B E Y \mathrm{KO}$ mitoribosomes may have a defect in mtIF3 recruitment and subunit association. While the studies of mitochondrial SSU assembly are still in their infancy $(81,83,87)$, our data provide novel insights into the composition of a late SSU assembly intermediate and establish a hierarchical relationship between some of its constituents.

Interestingly, the molecular mechanism proposed here (Figure 8) shows striking parallels to the late stages of the cytosolic/archeal SSU biogenesis catalysed by the adenylate kinase Fap7/hCINAP (96). Similar to YBEY, Fap7 forms a 
stoichiometric complex with uS11/Rps14 (97) and helps to recruit it to the nascent SSU (98), which represents a final checkpoint before the fully assembled SSU is released for translation (99). In fact, all known uS11 homologues have a long disordered positively charged $\mathrm{C}$-terminal extension, which needs to be correctly positioned in the vicinity of the helix-45 of the SSU rRNA (Figure 6E) (100). This requires the action of a dedicated chaperone (97). Fap7 also facilitates the association of the cytosolic uS11 with eS26 (101), which, by blocking the $3^{\prime}$-end of the $18 \mathrm{~S}$ rRNA, is positionally and functionally analogous to the mitochondrial $\mathrm{mS} 37$ (88). Therefore, it appears that in human cells conceptually similar mechanisms operate to accomplish the assembly of both cytosolic and mitochondrial SSUs.

Several questions regarding the molecular mechanism of YBEY in human mitochondria remain to be answered. How is uS11m loading on the nascent SSU performed? What is the role of other YBEY-interacting factors, such as ERAL1 and p32? Involvement of ERAL1 in mitochondrial SSU biogenesis and the associated mitochondrial diseases were reported (102-104), and physical and genetic interactions between bacterial Era and YbeY were described $(84,85)$. Moreover, the importance of Era for correct positioning of $\mathrm{uS} 11$ and recruitment of $\mathrm{bS} 21$ was demonstrated (86). Yet, the exact molecular role of ERAL1 in the YBEY pathway that we propose, is still elusive.

The major, stoichiometric partner of YBEY, p32, is a deeply conserved eukaryotic protein with a profound impact on the mitochondrial gene expression $(71,79)$. Our purification experiments suggest that $\mathrm{p} 32$ enhances the intrinsically poor solubility of YBEY, which may be due to the unfavourable overall charge of human YBEY (pI 7.04). Interestingly, most bacterial YbeY proteins, including those from Proteobacteria and Cyanobacteria, are highly negatively charged (Supplementary Figure S11). In contrast, eukaryotic YBEY homologues, with the exception of photosynthesizing clades, where YBEY appears to localize in chloroplasts (16), are neutral or slightly positive. Interestingly, this shift in charge coincides with the evolutionary emergence of the mitochondrial p32/MAM33 protein family (105), which may help maintaining the solubility and negative charge of YBEY-containing complexes. The latter property is likely important for the interaction of YBEY with functionally relevant protein partners, such as uS11m.

The association of YBEY with LSU proteins (Figure 5A, $\mathrm{B}, \mathrm{D})$ and the truncations in domain I of $16 \mathrm{~S}$ rRNA in $Y B E Y$ KO cells (Supplementary Figure S5G, H), where these proteins bind, were further intriguing findings. Together with the decrease of some ribosomal proteins and LSU biogenesis factors in $Y B E Y \mathrm{KO}$ cells (Figure 6G, H), these observations suggest that LSU assembly is somewhat perturbed by the loss of YBEY too. Negative effects on the LSU side in the absence of YBEY have also been described in $E$. coli and in chloroplasts $(8,16)$. It is, therefore, tempting to hypothesize the existence of a YBEY-mediated crosstalk between the SSU and LSU biogenesis pathways. Interestingly, the yeast p32 homologue has recently been shown to participate in LSU assembly (106); due to its negative charge, it binds several LSU proteins and prevents their aggregation. Thus, it appears conceivable that the effect of $Y B E Y \mathrm{KO}$ on the mitochondrial LSU is p32-mediated, and indeed the association of $\mathrm{p} 32$ with the LSU was significantly decreased in YBEY KO cells (Figure 6G). On the other hand, a heterotrimeric Trypanosoma brucei p32 homologue (also known as mt-SAF16/19/25) has recently been identified as part of the mitochondrial SSU 'assemblosome' (94). In light of the importance of p32 as a disease-associated and cancer-promoting protein $(72,77,78)$, the discovery of its tight association with YBEY and mitoribosome assembly may guide future mechanistic studies of its so-far elusive molecular functions.

Yet another puzzling aspect is the observed RNase activity of YBEY. Apparently conserved from bacteria to humans $(5,12,21)$, it is obviously not required for rRNA processing in human mitochondria (Figure 4D, E). Indeed, unlike mitochondrial RNase $\mathrm{P}$ and ELAC2 knockouts, resulting in accumulation of unprocessed rRNA precursors $(24,25,107,108)$, no such phenotype was observed when $Y B E Y$ was inactivated (Figure 4C). Moreover, substitution H128A, which lowers the RNase activity of the recombinant human enzyme, does not affect its ability to complement a $Y B E Y \mathrm{KO}$, similar to the equivalent substitution in $E$. coli (8). Likewise, substitution R55A, which severely impairs the RNase activity of bacterial YbeY $(5,12)$, fully complements $Y B E Y$ deletion in humans and B. subtilis (3) and restores $16 \mathrm{~S}$ rRNA processing in $E$. coli (8), B. subtilis (3) and Liberibacter asiaticus (19). These observations suggest that the apparent RNase activity of YBEY is not necessarily related to ribosome biogenesis, calling for further studies to clarify its nature and significance.

\section{DATA AVAILABILITY}

The RNA-Seq datasets generated during this study are deposited at the Gene Expression Omnibus (NCBI) and accessible through the GEO Series accession number GSE134960. Scripts to reproduce the RNA-Seq analysis are deposited at Zenodo (https://doi.org/10.5281/zenodo. 3341191). The mass spectrometry proteomics data have been deposited to the ProteomeXchange Consortium via the PRIDE partner repository with the dataset identifiers PXD014959, PXD015310.

\section{SUPPLEMENTARY DATA}

Supplementary Data are available at NAR Online.

\section{ACKNOWLEDGEMENTS}

The authors wish to thank Soufiane Rhermoul and Timothée Vincent for technical assistance, Valérie Demais and Cathy Royer (Plateforme Imagerie In Vitro, CNRS, UPS 3156, University of Strasbourg) for their help with electron microscopy, Hélène Puccio (IGBMC, Strasbourg) for access to Seahorse, Jérôme Mutterer and Mathieu Erhardt (microscopy and cellular imaging, IBMP, CNRS, Strasbourg) for their help with FLIM-FRET.

\section{FUNDING}

Austrian Science Fund (FWF) [W1207 and P25983 to W.R.]; University of Strasbourg as LabEx MitoCross 
[ANR-11-LABX-0057_MITOCROSS to An.S., N.E., I.T. and Al.S.]; IdEx - Attractivité [ANR-10-IDEX-0002-02 to Al.S.]; IdEx Equipement mi-lourd 2015 (to J.C., L.K. and P.H.); LabEx NetRNA [ANR-10-LABX-0036-NETRNA to J.C., L.K. and P.H.]; Agence Nationale de la Recherche [ANR-19-CE11-0013 to Al.S.]. Funding for open access charge: Agence Nationale de la Recherche [ANR-19-CE110013 to Al.S.].

Conflict of interest statement. None declared.

\section{REFERENCES}

1. Connolly,K. and Culver,G. (2009) Deconstructing ribosome construction. Trends Biochem. Sci., 34, 256-263.

2. Gil,R., Silva,F.J., Pereto,J. and Moya,A. (2004) Determination of the core of a minimal bacterial gene set. Microbiol. Mol. Biol. Rev., $\mathbf{6 8}, 518-537$

3. Baumgardt,K., Gilet,L., Figaro,S. and Condon,C. (2018) The essential nature of YqfG, a YbeY homologue required for $3^{\prime}$ maturation of Bacillus subtilis 16S ribosomal RNA is suppressed by deletion of RNase R. Nucleic Acids Res., 46, 8605-8615.

4. Rasouly,A., Davidovich,C. and Ron,E.Z. (2010) The heat shock protein YbeY is required for optimal activity of the $30 \mathrm{~S}$ ribosomal subunit. J. Bacteriol., 192, 4592-4596.

5. Jacob,A.I., Köhrer,C., Davies,B.W., RajBhandary,U.L. and Walker,G.C. (2013) Conserved bacterial RNase YbeY plays key roles in $70 \mathrm{~S}$ ribosome quality control and $16 \mathrm{~S}$ rRNA maturation. Mol. Cell, 49, 427-438.

6. Leskinen,K., Varjosalo,M. and Skurnik,M. (2015) Absence of YbeY RNase compromises the growth and enhances the virulence plasmid gene expression of Yersinia enterocolitica O:3. Microbiology, 161, 285-299.

7. Vercruysse,M., Köhrer,C., Davies,B.W., Arnold,M.F., Mekalanos,J.J., RajBhandary,U.L. and Walker,G.C. (2014) The highly conserved bacterial R Nase YbeY is essential in Vibrio cholerae, playing a critical role in virulence, stress regulation, and RNA processing. PLoS Pathog., 10, e1004175.

8. Davies,B.W., Köhrer,C., Jacob,A.I., Simmons,L.A., Zhu,J., Aleman,L.M., Rajbhandary,U.L. and Walker,G.C. (2010) Role of Escherichia coli $\mathrm{YbeY}$, a highly conserved protein, in rRNA processing. Mol. Microbiol., 78, 506-518.

9. Pandey,S.P., Winkler,J.A., Li,H., Camacho,D.M., Collins,J.J. and Walker,G.C. (2014) Central role for RNase YbeY in Hfq-dependent and Hfq-independent small-RNA regulation in bacteria. BMC Genomics, 15, 121.

10. Ohyama,H., Sakai,T., Agari,Y., Fukui,K., Nakagawa,N., Shinkai,A., Masui,R. and Kuramitsu,S. (2014) The role of ribonucleases in regulating global mRNA levels in the model organism Thermus thermophilus HB8. BMC Genomics, 15, 386.

11. Pandey,S.P., Minesinger,B.K., Kumar,J. and Walker,G.C. (2011) A highly conserved protein of unknown function in Sinorhizobium meliloti affects sRNA regulation similar to Hfq. Nucleic Acids Res., 39, 4691-4708.

12. Saramago,M., Peregrina,A., Robledo,M., Matos,R.G., Hilker,R., Serrania,J., Becker,A., Arraiano,C.M. and Jiménez-Zurdo,J.I. (2017) Sinorhizobium meliloti $\mathrm{YbeY}$ is an endoribonuclease with unprecedented catalytic features, acting as silencing enzyme in riboregulation. Nucleic Acids Res., 45, 1371-1391.

13. Budnick,J.A., Sheehan,L.M., Colquhoun,J.M., Dunman,P.M., Walker,G.C., Roop,R.M. 2nd and Caswell,C.C. (2018) Endoribonuclease $\mathrm{YbeY}$ is linked to proper cellular morphology and virulence in Brucella abortus. J. Bacteriol., 200, e00105-18.

14. Möller,P., Busch,P., Sauerbrei,B., Kraus,A., Förstner,K.U., Wen,T.N., Overlöper,A., Lai,E.M. and Narberhaus,F. (2019) The $\mathrm{RNase} \mathrm{YbeY}$ is vital for ribosome maturation, stress resistance and virulence of the natural genetic engineer Agrobacterium tumefaciens. J. Bacteriol., 201, e00730-18.

15. Davies,B.W. and Walker,G.C. (2008) A highly conserved protein of unknown function is required by Sinorhizobium meliloti for symbiosis and environmental stress protection. J. Bacteriol., 190, $1118-1123$.
16. Liu,J., Zhou,W., Liu,G., Yang,C., Sun,Y., Wu,W., Cao,S., Wang,C., Hai,G., Wang,Z. et al. (2015) The conserved endoribonuclease $\mathrm{YbeY}$ is required for chloroplast ribosomal RNA processing in Arabidopsis. Plant Physiol., 168, 205-221.

17. McAteer,S.P., Sy,B.M., Wong,J.L., Tollervey,D., Gally,D.L. and Tree,J.J. (2018) Ribosome maturation by the endoribonuclease YbeY stabilizes a type 3 secretion system transcript required for virulence of enterohemorrhagic Escherichia coli. J. Biol. Chem., 293, 9006-9016.

18. Babu,V.M.P., Sankari,S., Budnick,J.A., Caswell,C.C. and Walker,G.C. (2020) Sinorhizobium meliloti YbeY is a zinc-dependent single-strand specific endoribonuclease that plays an important role in 16S ribosomal RNA processing. Nucleic Acids Res., 48, 332-348.

19. Zuo,R., de Oliveira,A., Bullita,E., Torino,M.I. Padgett-Pagliai,K.A., Gardner,C.L., Harrison,N.A., da Silva,D., Merli,M.L., Gonzalez,C.F. et al. (2019) Identification of flavonoids as regulators of YbeY activity in Liberibacter asiaticus. Environ. Microbiol., 21, 4822-4835.

20. Shajani,Z., Sykes,M.T. and Williamson,J.R. (2011) Assembly of bacterial ribosomes. Annu. Rev. Biochem., 80, 501-526.

21. Ghosal,A., Köhrer,C., Babu,V.M.P., Yamanaka,K., Davies,B.W., Jacob,A.I., Ferullo,D.J., Gruber,C.C., Vercruysse,M. and Walker,G.C. (2017) C21 orf57 is a human homologue of bacterial YbeY proteins. Biochem. Biophys. Res. Commun., 484, 612-617.

22. Calvo,S.E., Clauser,K.R. and Mootha,V.K. (2016) MitoCarta2.0: an updated inventory of mammalian mitochondrial proteins. Nucleic Acids Res., 44, D1251-D1257.

23. Ojala,D., Montoya,J. and Attardi,G. (1981) tRNA punctuation model of RNA processing in human mitochondria. Nature, 290, 470-474.

24. Holzmann,J., Frank,P., Löffler,E., Bennett,K.L., Gerner,C. and Rossmanith,W. (2008) RNase P without RNA: identification and functional reconstitution of the human mitochondrial tRNA processing enzyme. Cell, 135, 462-474.

25. Brzezniak,L.K., Bijata,M., Szczesny,R.J. and Stepien,P.P. (2011) Involvement of human ELAC2 gene product in $3^{\prime}$ end processing of mitochondrial tRNAs. RNA Biol., 8, 616-626.

26. Temperley,R.J., Wydro,M., Lightowlers, R.N. and Chrzanowska-Lightowlers,Z.M. (2010) Human mitochondrial mRNAs-like members of all families, similar but different. Biochim. Biophys. Acta, 1797, 1081-1085.

27. Arroyo,J.D., Jourdain,A.A., Calvo,S.E., Ballarano,C.A., Doench,J.G., Root,D.E. and Mootha,V.K. (2016) A genome-wide CRISPR death screen identifies genes essential for oxidative phosphorylation. Cell Metab., 24, 875-885.

28. Cong,L., Ran,F.A., Cox,D., Lin,S., Barretto,R., Habib,N., Hsu,P.D., Wu,X., Jiang,W., Marraffini,L.A. et al. (2013) Multiplex genome engineering using CRISPR/Cas systems. Science, 339, 819-823.

29. Morita,E., Arii,J., Christensen,D., Votteler,J. and Sundquist,W.I. (2012) Attenuated protein expression vectors for use in siRNA rescue experiments. BioTechniques, $\mathbf{0}, 1-5$.

30. Jourdain,A.A., Koppen,M., Wydro,M., Rodley,C.D., Lightowlers, R.N., Chrzanowska-Lightowlers,Z.M. and Martinou,J.C. (2013) GRSF1 regulates RNA processing in mitochondrial RNA granules. Cell Metab., 17, 399-410.

31. Schneider,C.A., Rasband,W.S. and Eliceiri,K.W. (2012) NIH Image to ImageJ: 25 years of image analysis. Nat. Methods, 9, 671-675.

32. Li,C.H. and Tam,P.K.S. (1998) An iterative algorithm for minimum cross entropy thresholding. Pattern Recogn. Lett., 19, 771-776.

33. Battich,N., Stoeger,T. and Pelkmans,L. (2013) Image-based transcriptomics in thousands of single human cells at single-molecule resolution. Nat. Methods, 10, 1127-1133.

34. Rizk,A., Paul,G., Incardona,P., Bugarski,M., Mansouri,M., Niemann,A., Ziegler,U., Berger,P. and Sbalzarini,I.F. (2014) Segmentation and quantification of subcellular structures in fluorescence microscopy images using Squassh. Nat. Protoc., 9, 586-596.

35. Schindelin,J., Arganda-Carreras,I., Frise,E., Kaynig,V., Longair,M., Pietzsch,T., Preibisch,S., Rueden,C., Saalfeld,S., Schmid,B. et al. (2012) Fiji: an open-source platform for biological-image analysis. Nat. Methods, 9, 676-682.

36. Waterhouse,B.R., Gijsen,M., Barber,P.R., Tullis,I.D., Vojnovic,B. and Kong,A. (2011) Assessment of EGFR/HER2 dimerization by 
FRET-FLIM utilizing Alexa-conjugated secondary antibodies in relation to targeted therapies in cancers. Oncotarget, 2, 728-736.

37. Kenworthy,A.K. (2001) Imaging protein-protein interactions using fluorescence resonance energy transfer microscopy. Methods, 24, 289-296.

38. He,L., Chinnery,P.F., Durham,S.E., Blakely,E.L., Wardell,T.M., Borthwick,G.M., Taylor,R.W. and Turnbull,D.M. (2002) Detection and quantification of mitochondrial DNA deletions in individual cells by real-time PCR. Nucleic Acids Res., 30, e68.

39. Rossmanith,W., Freilinger,M., Roka,J., Raffelsberger,T., Moser-Thier,K., Prayer,D., Bernert,G. and Bittner,R.E. (2008) Isolated cytochrome c oxidase deficiency as a cause of MELAS. $J$. Med. Genet., 45, 117-121.

40. Quinlan,A.R. and Hall,I.M. (2010) BEDTools: a flexible suite of utilities for comparing genomic features. Bioinformatics, 26, 841-842.

41. Martin,M. (2011) Cutadapt removes adapter sequences from high-throughput sequencing reads. EMBnet J., 17, 3 .

42. Hoffmann,S., Otto,C., Kurtz,S., Sharma,C.M., Khaitovich,P., Vogel,J., Stadler,P.F. and Hackermüller,J. (2009) Fast mapping of short sequences with mismatches, insertions and deletions using index structures. PLoS Comput. Biol., 5, e1000502.

43. Li,H., Handsaker,B., Wysoker,A., Fennell,T., Ruan,J., Homer,N., Marth,G., Abecasis,G., Durbin,R. and Genome Project Data Processing, S. (2009) The sequence Alignment/Map format and SAMtools. Bioinformatics, 25, 2078-2079.

44. Liao,Y., Smyth,G.K. and Shi,W. (2014) featureCounts: an efficient general purpose program for assigning sequence reads to genomic features. Bioinformatics, 30, 923-930.

45. Love,M.I., Huber,W. and Anders,S. (2014) Moderated estimation of fold change and dispersion for RNA-seq data with DESeq2. Genome Biol., 15, 550 .

46. Freese,N.H., Norris,D.C. and Loraine,A.E. (2016) Integrated genome browser: visual analytics platform for genomics. Bioinformatics, 32, 2089-2095.

47. Chicher,J., Simonetti,A., Kuhn,L., Schaeffer,L., Hammann,P., Eriani,G. and Martin,F. (2015) Purification of mRNA-programmed translation initiation complexes suitable for mass spectrometry analysis. Proteomics, 15, 2417-2425.

48. Waltz,F., Nguyen,T.T., Arrive,M., Bochler,A., Chicher,J., Hammann,P., Kuhn,L., Quadrado,M., Mireau,H., Hashem, Y. et al. (2019) Small is big in Arabidopsis mitochondrial ribosome. Nat. Plants, 5, 106-117.

49. Zybailov,B., Mosley,A.L., Sardiu,M.E., Coleman,M.K., Florens,L. and Washburn,M.P. (2006) Statistical analysis of membrane proteome expression changes in Saccharomyces cerevisiae. $J$. Proteome Res., 5, 2339-2347.

50. Smirnov,A., Förstner,K.U., Holmqvist,E., Otto,A., Günster,R., Becher,D., Reinhardt,R. and Vogel,J. (2016) Grad-seq guides the discovery of ProQ as a major small RNA-binding protein. Proc. Natl. Acad. Sci. U.S.A., 113, 11591-11596.

51. Smirnov,A., Schneider,C., Hör,J. and Vogel,J. (2017) Discovery of new RNA classes and global RNA-binding proteins. Curr. Opin. Microbiol., 39, 152-160.

52. Strauss,F.J., Stähli,A., Beer,L., Mitulović,G., Gilmozzi,V., Haspel,N., Schwab,G. and Gruber,R. (2018) Acid bone lysate activates TGFbeta signalling in human oral fibroblasts. Sci. Rep., 8 , 16065.

53. Fukasawa,Y., Tsuji,J., Fu,S.C., Tomii,K., Horton,P. and Imai,K. (2015) MitoFates: improved prediction of mitochondrial targeting sequences and their cleavage sites. Mol. Cell. Proteomics, 14, $1113-1126$.

54. Emanuelsson,O., Brunak,S., von Heijne,G. and Nielsen,H. (2007) Locating proteins in the cell using TargetP, SignalP and related tools. Nat. Protoc., 2, 953-971.

55. Claros,M.G. and Vincens,P. (1996) Computational method to predict mitochondrially imported proteins and their targeting sequences. Eur. J. Biochem., 241, 779-786.

56. Jiang,J., Zhang,Y., Krainer,A.R. and Xu,R.M. (1999) Crystal structure of human $\mathrm{p} 32$, a doughnut-shaped acidic mitochondrial matrix protein. Proc. Natl. Acad. Sci. U.S.A., 96, 3572-3577.

57. Smirnov,A., Entelis,N., Martin,R.P. and Tarassov,I. (2011) Biological significance of 5S rRNA import into human mitochondria: role of ribosomal protein MRP-L18. Genes Dev., 25, 1289-1305.

58. Papadopoulos,J.S. and Agarwala,R. (2007) COBALT: constraint-based alignment tool for multiple protein sequences. Bioinformatics, 23, 1073-1079.

59. Källberg,M., Wang,H., Wang,S., Peng,J., Wang,Z., Lu,H. and Xu,J. (2012) Template-based protein structure modeling using the RaptorX web server. Nat. Protoc., 7, 1511-1522.

60. Kaushal,P.S., Sharma,M.R., Booth,T.M., Haque,E.M., Tung,C.S., Sanbonmatsu,K.Y., Spremulli,L.L. and Agrawal,R.K. (2014) Cryo-EM structure of the small subunit of the mammalian mitochondrial ribosome. Proc. Natl. Acad. Sci. U.S.A., 111, 7284-7289.

61. Brown,A., Amunts,A., Bai,X.C., Sugimoto,Y., Edwards,P.C., Murshudov,G., Scheres,S.H. and Ramakrishnan,V. (2014) Structure of the large ribosomal subunit from human mitochondria. Science, 346, 718-722.

62. Gasteiger,E., Hoogland,C., Gattiker,A., Duvaud,S., Wilkins,M.R., Appel,R.D. and Bairoch,A. (2005) In: Walker,JM (ed). The Proteomics Protocols Handbook. Humana Press, pp. 571-607.

63. Letunic,I. and Bork,P. (2019) Interactive Tree Of Life (iTOL) v4: recent updates and new developments. Nucleic Acids Res., 47, W256-W259.

64. Altschul,S.F., Gish,W., Miller,W., Myers,E.W. and Lipman,D.J. (1990) Basic local alignment search tool. J. Mol. Biol., 215, 403-410.

65. Motulsky,H. (2010) Intuitive Biostatistics: A Nonmathematical Guide to Statistical Thinking. Completely revised. 2nd edn. Oxford University Press, NY.

66. Uhlén,M., Oksvold,P., Älgenäs,C., Hamsten,C., Fagerberg,L., Klevebring,D., Lundberg,E., Odeberg,J., Pontén,F., Kondo,T. et al. (2012) Antibody-based protein profiling of the human chromosome 21. Mol. Cell. Proteomics, 11, M111.013458.

67. Emanuelsson,O., Nielsen,H., Brunak,S. and von Heijne,G. (2000) Predicting subcellular localization of proteins based on their N-terminal amino acid sequence. J. Mol. Biol., 300, 1005-1016.

68. Vincent,A.E., Ng,Y.S., White,K., Davey,T., Mannella,C., Falkous,G., Feeney,C., Schaefer,A.M., McFarland,R., Gorman,G.S. et al. (2016) The spectrum of mitochondrial ultrastructural defects in mitochondrial myopathy. Sci. Rep., 6, 30610.

69. Guerrero-Castillo,S., Baertling,F., Kownatzki,D., Wessels,H.J., Arnold,S., Brandt,U. and Nijtmans,L. (2017) The assembly pathway of mitochondrial respiratory chain complex I. Cell Metab., 25, 128-139.

70. Pearce,S.F., Rebelo-Guiomar,P., D'Souza,A.R., Powell,C.A., Van Haute,L. and Minczuk,M. (2017) Regulation of mammalian mitochondrial gene expression: recent advances. Trends Biochem. Sci., 42, 625-639.

71. Yagi,M., Uchiumi,T., Takazaki,S., Okuno,B., Nomura,M., Yoshida,S., Kanki,T. and Kang,D. (2012) p32/gC1qR is indispensable for fetal development and mitochondrial translation: importance of its RNA-binding ability. Nucleic Acids Res., 40, 9717-9737.

72. Feichtinger,R.G., Olahova,M., Kishita,Y., Garone,C., Kremer,L.S., Yagi,M., Uchiumi,T., Jourdain,A.A., Thompson,K., D'Souza,A.R. et al. (2017) Biallelic ClQBP mutations cause severe neonatal-, childhood-, or later-onset cardiomyopathy associated with combined respiratory-chain deficiencies. Am. J. Hum. Genet., 101, 525-538.

73. Saito,T., Uchiumi,T., Yagi,M., Amamoto,R., Setoyama,D., Matsushima,Y. and Kang,D. (2017) Cardiomyocyte-specific loss of mitochondrial $\mathrm{p} 32 / \mathrm{Clqbp}$ causes cardiomyopathy and activates stress responses. Cardiovasc. Res., 113, 1173-1185.

74. Yagi,M., Uchiumi,T., Sagata,N., Setoyama,D., Amamoto,R., Matsushima,Y. and Kang,D. (2017) Neural-specific deletion of mitochondrial $\mathrm{p} 32 / \mathrm{C} 1 \mathrm{qbp}$ leads to leukoencephalopathy due to undifferentiated oligodendrocyte and axon degeneration. Sci. Rep., 7, 15131 .

75. Liu,Y., Leslie,P.L., Jin,A., Itahana,K., Graves,L.M. and Zhang,Y. (2017) p32 heterozygosity protects against age- and diet-induced obesity by increasing energy expenditure. Sci. Rep., 7, 5754 .

76. Muta,T., Kang,D., Kitajima,S., Fujiwara,T. and Hamasaki,N. (1997) p32 protein, a splicing factor 2 -associated protein, is localized in mitochondrial matrix and is functionally important in maintaining oxidative phosphorylation. J. Biol. Chem., 272, 24363-24370. 
77. McGee,A.M., Douglas,D.L., Liang,Y., Hyder,S.M. and Baines,C.P. (2011) The mitochondrial protein Clqbp promotes cell proliferation, migration and resistance to cell death. Cell Cycle, 10, 4119-4127.

78. Fogal,V., Richardson,A.D., Karmali,P.P., Scheffler,I.E., Smith,J.W. and Ruoslahti,E. (2010) Mitochondrial p32 protein is a critical regulator of tumor metabolism via maintenance of oxidative phosphorylation. Mol. Cell. Biol., 30, 1303-1318.

79. Hu,M., Crawford,S.A., Henstridge,D.C., Ng,I.H., Boey,E.J., Xu,Y., Febbraio,M.A., Jans,D.A. and Bogoyevitch,M.A. (2013) p32 protein levels are integral to mitochondrial and endoplasmic reticulum morphology, cell metabolism and survival. Biochem. J., 453, 381-391.

80. Leucci,E., Vendramin,R., Spinazzi,M., Laurette,P., Fiers,M., Wouters,J., Radaelli,E., Eyckerman,S., Leonelli,C., Vanderheyden,K. et al. (2016) Melanoma addiction to the long non-coding RNA SAMMSON. Nature, 531, 518-522.

81. Bogenhagen,D.F., Ostermeyer-Fay,A.G., Haley,J.D. and Garcia-Diaz,M. (2018) Kinetics and mechanism of mammalian mitochondrial ribosome assembly. Cell Rep., 22, 1935-1944.

82. Zeng,R., Smith,E. and Barrientos,A. (2018) Yeast mitoribosome large subunit assembly proceeds by hierarchical incorporation of protein clusters and modules on the inner membrane. Cell Metab., 27, 645-656.

83. Bogenhagen,D.F., Martin,D.W. and Koller,A. (2014) Initial steps in RNA processing and ribosome assembly occur at mitochondrial DNA nucleoids. Cell Metab., 19, 618-629.

84. Vercruysse,M., Köhrer,C., Shen,Y., Proulx,S., Ghosal,A., Davies,B.W., RajBhandary,U.L. and Walker,G.C. (2016) Identification of YbeY-protein interactions involved in 16S rRNA maturation and stress regulation in Escherichia coli. MBio, 7, e01785-16.

85. Ghosal,A., Babu,V.M.P. and Walker,G.C. (2018) Elevated levels of Era GTPase improve growth, 16S rRNA processing, and 70S ribosome assembly of Escherichia coli lacking highly conserved multifunctional YbeY endoribonuclease. J. Bacteriol., 200, e00278-18

86. Razi,A., Davis,J.H., Hao,Y., Jahagirdar,D., Thurlow,B., Basu,K., Jain,N., Gomez-Blanco,J., Britton,R.A., Vargas,J. et al. (2019) Role of Era in assembly and homeostasis of the ribosomal small subunit. Nucleic Acids Res., 47, 8301-8317.

87. De Silva,D., Tu,Y.T., Amunts,A., Fontanesi,F. and Barrientos,A. (2015) Mitochondrial ribosome assembly in health and disease. Cell Cycle, 14, 2226-2250.

88. Amunts,A., Brown,A., Toots,J., Scheres,S.H.W. and Ramakrishnan,V. (2015) Ribosome. The structure of the human mitochondrial ribosome. Science, 348, 95-98.

89. Greber,B.J., Bieri,P., Leibundgut,M., Leitner,A., Aebersold,R., Boehringer,D. and Ban,N. (2015) Ribosome. The complete structure of the $55 \mathrm{~S}$ mammalian mitochondrial ribosome. Science, $\mathbf{3 4 8}$, 303-308.

90. Tu,Y.T. and Barrientos,A. (2015) The human mitochondrial DEAD-Box protein DDX28 resides in RNA granules and functions in mitoribosome assembly. Cell Rep., 10, 854-864.

91. Antonicka,H. and Shoubridge,E.A. (2015) Mitochondrial RNA granules are centers for posttranscriptional RNA processing and ribosome biogenesis. Cell Rep., 10, 920-932.

92. Koripella,R.K., Sharma,M.R., Haque,M.E., Risteff,P., Spremulli,L.L. and Agrawal,R.K. (2019) Structure of human mitochondrial translation initiation factor 3 bound to the small ribosomal subunit. iScience, 12, 76-86.

93. Van Duin,J. and Wijnands, R. (1981) The function of ribosomal protein S21 in protein synthesis. Eur. J. Biochem., 118, 615-619.
94. Saurer,M., Ramrath,D.J.F., Niemann,M., Calderaro,S., Prange,C., Mattei,S., Scaiola,A., Leitner,A., Bieri,P., Horn,E.K. et al. (2019) Mitoribosomal small subunit biogenesis in trypanosomes involves an extensive assembly machinery. Science, 365, 1144-1149.

95. Haque,M.E., Koc,H., Cimen,H., Koc,E.C. and Spremulli,L.L. (2011) Contacts between mammalian mitochondrial translational initiation factor 3 and ribosomal proteins in the small subunit. Biochim. Biophys. Acta, 1814, 1779-1784.

96. Bai,D., Zhang,J., Li,T., Hang,R., Liu,Y., Tian,Y., Huang,D., Qu,L., Cao,X., Ji,J. et al. (2016) The ATPase hCINAP regulates 18S rRNA processing and is essential for embryogenesis and tumour growth. Nat. Commun., 7, 12310.

97. Hellmich,U.A., Weis,B.L., Lioutikov,A., Wurm,J.P., Kaiser,M., Christ,N.A., Hantke,K., Kötter,P., Entian,K.D., Schleiff,E. et al. (2013) Essential ribosome assembly factor Fap7 regulates a hierarchy of RNA-protein interactions during small ribosomal subunit biogenesis. Proc. Natl. Acad. Sci. U.S.A., 110, 15253-15258.

98. Loc'h,J., Blaud,M., Rety,S., Lebaron,S., Deschamps,P., Bareille,J., Jombart,J., Robert-Paganin,J., Delbos,L., Chardon,F. et al. (2014) RNA mimicry by the fap7 adenylate kinase in ribosome biogenesis. PLoS Biol., 12, e1001860.

99. Ghalei,H., Trepreau,J., Collins,J.C., Bhaskaran,H., Strunk,B.S. and Karbstein,K. (2017) The ATPase Fap7 tests the ability to carry out translocation-like conformational changes and releases Dim1 during 40S ribosome maturation. Mol. Cell, $\mathbf{6 8}, 1155$.

100. Melnikov,S., Manakongtreecheep,K. and Söll,D. (2018) Revising the structural diversity of ribosomal proteins across the three domains of life. Mol. Biol. Evol., 35, 1588-1598.

101. Pena,C., Schütz,S., Fischer,U., Chang,Y. and Panse,V.G. (2016) Prefabrication of a ribosomal protein subcomplex essential for eukaryotic ribosome formation. Elife, 5, e21755.

102. Chatzispyrou,I.A., Alders,M., Guerrero-Castillo,S., Zapata Perez,R., Haagmans,M.A., Mouchiroud,L., Koster,J., Ofman,R., Baas,F., Waterham,H.R. et al. (2017) A homozygous missense mutation in ERAL1, encoding a mitochondrial rRNA chaperone, causes Perrault syndrome. Hum. Mol. Genet., 26, 2541-2550.

103. Dennerlein,S., Rozanska,A., Wydro,M., Chrzanowska-Lightowlers,Z.M. and Lightowlers,R.N. (2010) Human ERAL1 is a mitochondrial RNA chaperone involved in the assembly of the $28 \mathrm{~S}$ small mitochondrial ribosomal subunit. Biochem. J., 430, 551-558.

104. Uchiumi,T., Ohgaki,K., Yagi,M., Aoki,Y., Sakai,A., Matsumoto,S. and Kang,D. (2010) ERAL1 is associated with mitochondrial ribosome and elimination of ERAL1 leads to mitochondrial dysfunction and growth retardation. Nucleic Acids Res., 38, $5554-5568$

105. Kauko,A. and Lehto,K. (2018) Eukaryote specific folds: part of the whole. Proteins, 86, 868-881.

106. Hillman,G.A. and Henry,M.F. (2019) The yeast protein Mam33 functions in the assembly of the mitochondrial ribosome. J. Biol. Chem., 294, 9813-9829.

107. Rackham,O., Busch,J.D., Matic,S., Siira,S.J., Kuznetsova,I., Atanassov,I., Ermer,J.A., Shearwood,A.M., Richman,T.R., Stewart,J.B. et al. (2016) Hierarchical RNA processing is required for mitochondrial ribosome assembly. Cell Rep., 16, 1874-1890.

108. Siira,S.J., Rossetti,G., Richman,T.R., Perks,K., Ermer,J.A., Kuznetsova,I., Hughes,L., Shearwood,A.J., Viola,H.M., Hool,L.C. et al. (2018) Concerted regulation of mitochondrial and nuclear non-coding RNAs by a dual-targeted RNase Z. EMBO Rep., 19, e46198. 